
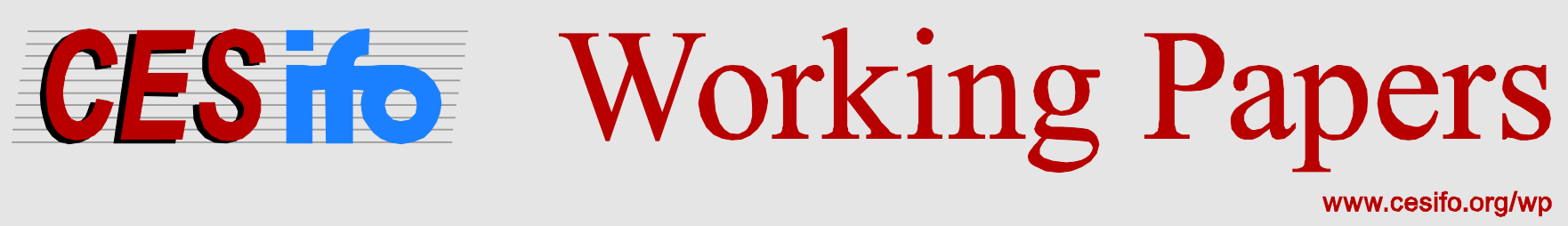

\title{
Treasury Auctions and Secondary Market Dynamics. An Analysis Based on the MTS Market for Italy.
}

\author{
Gianluca Cafiso
}

CESIFO WORKING PAPER NO. 5357

CAtegory 1: Public FinAnCE

MAY 2015

An electronic version of the paper may be downloaded

- from the SSRN website:

- from the RePEc website:

- from the CESifo website:

WWw.SSRN.com

www.RePEc.org

www.CESifo-group.org/wp 


\title{
Treasury Auctions and Secondary Market Dynamics. An Analysis Based on the MTS Market for Italy.
}

\begin{abstract}
Auctions of government bonds are the main allotment method used by the Treasury of advanced economies. Previous research has found that auctions have an influence on the market yield days before they take place, and underpricing is usually spotted when their outcome is compared with contemporaneous market quotes. The objective of this research is to investigate deeper and more accurately these two findings by taking Italy as a case study. Our results question the so-called auction cycle and do not signal underpricing when a perfect matching between the auctioned bond and the market quote used is ensured.
\end{abstract}

JEL-Code: G120, G140, G180.

Keywords: primary market, secondary market, MTS market, treasury auctions, government bonds, market micro-structure, regime volatility.

\author{
Gianluca Cafiso \\ University of Catania \\ Corso Italia 55 \\ Italy - 95129 Catania \\ gcafiso@unict.it
}

Webpage: www.sites.google.com/site/giancafiso.

April 2015 


\section{Contents}

1 Introduction $\quad 1$

2 Auctions, secondary market dynamics and primary dealers' behavior 2

3 Data $r$

4 The influence of auctions on the secondary market $\quad 9$

4.1 Auction cycles . . . . . . . . . . . . . . . . . . . . . . . . . . . . . 10

4.2 The influence of auctions with respect to volatility . . . . . . . . . . . . . . 14

4.3 A robustness check: the case of five 10 -year BTPs $\ldots \ldots \ldots \ldots$

4.4 Discussion of the results . . . . . . . . . . . . . . . . . . . . . . . . 19

5 Auction results with respect to Market values $r$

6 Conclusions $r$

$\begin{array}{lr}\text { References } & 26\end{array}$

$\begin{array}{lr}\text { Appendix I. Tables and Figures } & 29\end{array}$

Appendix II. (available on-line) 32

\section{Acknowledgments}

I thank Alessandro Missale, Davide Dottori and Urszula Szczerbowicz for suggestions and references about this topic. A special thank to Tiziano Ropele for helping to gain essential information on the data published by Banca d'Italia, as well as to the statistics division of Banca d'Italia for producing such information. I also thank the MTS staff in Rome, particularly Ciro Pietroluongo, for providing me with data on a selection of Italian government bonds. I discussed some features of the auction procedure with staff at the Italian Treasury, I thank Roberto Di Veglia for the clarifications. Benedetto Matarazzo helped me with some technicalities. All the results, hypotheses and conclusions are my own, the author is the only responsible for what is in the text. 


\section{Introduction}

The market of government bonds is one of the most important components of the broader financial market. Access to this market means the ability of a Sovereign to finance its deficit and roll-over its debt autonomously. The cost of such financing is defined by the result of primary-market operations (Wolswijk and De Haan, 2005). In applied analyses many researchers consider as an indicator of such cost the yield in the secondary market (among others, Andritzky, 2012; Beltran et al., 2013). However, systematic differences between the result of primary-market operations and contemporaneous market quotes were spotted by previous research (Goldreich, 2007); we observed such differences as well in a previous research of ours (Cafiso, 2014). Furthermore, it has been suggested (Lou et al., 2013) that the dynamics of the market yield is influenced by primary-market operations. The analysis in this paper aims to shed light on the contemporaneous evolution of the primary and the secondary market of government bonds.

Given that the main operations in the primary market are auctions (AFME, 2014), our first objective is to study the evolution of the secondary market when auctions take place and to check whether such evolution is conditioned by volatility in the market. The scope is to search for regularities across auctions. Secondly, we aim to compare auction results against contemporaneous market quotes. In this regard, we want to provide information about the sign and distribution of their difference which, among other things, can help to assess the convenience of auctions with respect to alternative allotment methods. Given the volume of bonds involved, even small differences may sum up to additional billions in terms of debt servicing.

The analysis is based on auctions of Italy's government bonds and considers their influence on the MTS market, the wholesale market of Italian government bonds. The period under consideration is from January 2002 to December 2014 (13 years). After a section vowed to explain the main features of the primary and secondary market and to discuss primary dealers' behavior at times of auctions (section 2), and a section to explain the data used (section 3), the analysis is developed into two parts. The first part deals with the evolution of the MTS market when auctions occur without considering the result of the auction itself (section

4). The results of auctions are instead compared to contemporaneous market quotes in the second part (section 5). Given tight data constraints and some peculiarities of Italian auctions, this analysis is less extensive than the one in the first part. We draw the main conclusions of the paper in section 6.

The edges of our analysis with respect to previous ones are the following. First and foremost, the consistency of the data used. These are all taken from the same source, refer to a specific secondary market (the MTS), and both the auction data and the market quotes are subject to the same traceable transformations. Secondly, we ensure the highest level of accuracy since a perfect matching between the auctioned bond and the market 
quote of the same bond is maintained. Thirdly, we differentiate across auctions of new bonds, of the on-the-run bond and of off-the-run bonds; this will bring new insights with respect to previous analyses. Fourth, robustness is assessed by considering the evolution of specif bonds. In a nutshell, the main results of our analysis are: i) an increase of the market yield is observed at the auction day; ii) the so-called auction cycle found in previous studies seems more a result of aggregation than a widespread pattern; iii) the size of the auction influence on the secondary market seems to depend also upon the level of volatility in the market; iv) underpricing is not detected for Italy, the amount of the difference between the auction price and the market price seems correlated with some auction-related variables to a certain extent; v) auctions of new bonds seem to have a deeper influence on the market yield of a bond already traded than further auctions of its own. The data show also that the Italian Treasury partly changed its issuing policy during the turmoil periods under consideration.

Our contribution to this branch of literature consists in the finding that the auction cycle is not a widespread pattern across auctions and that its width is very limited when it occurs, differently from what seems from previous works. Secondly, underpricing does not emerge for Italy, consequently this cannot be considered as a general result regarding all markets at all times. On the whole, we believe that the discussion in the paper is reach of insights about the relationship between the primary and secondary market.

\section{Auctions, secondary market dynamics and primary dealers' behavior}

The primary market of government bonds (GBs, hereinafter) is for the issuance of new bonds or new amounts of an already outstanding bond; this is where the borrower obtains the loan. One of the two counterparts is the public authority legally entitled to issue the bonds, to which we refer here as the Treasury. The secondary market is the one where already issued bonds are traded between different agents. Transactions in the secondary market regard mainly private entities, but also public institutions operate in this market; to wit, for monetary policy (Rogers et al., 2014) or strategic debt management (Missale et al., 2002). ${ }^{1}$

The result of the operations in the primary market defines the cost of the loan that the Treasury obtains by selling the bonds and, ultimately, the cost of the (marketable) public debt. Broadly speaking, there are three methods to place bonds through the primary market: 1) auctions, 2) syndicated loans, 3) offers to the public; the by-far larger amount of GBs is placed through auctions (AFME, 2014).

Participation to auctions is usually restricted to a limited number of financial institutions named Primary Dealers. In some countries, there may be a smaller group among the primary dealers which enjoys special

\footnotetext{
${ }^{1}$ The primary market is an event-working market; to wit, only when the Treasury decides an operation it works. On the contrary, the secondary market is a continuous-time working market following the working hours of the different platforms/submarkets (regulated) which it encompasses as well as over-the-counter transactions.
} 
privileges against the fulfilling of underwriting and market-making obligations in the secondary market; as for this, Massa and Simonov (2003) suggest that different traders have a different influence on the market. ${ }^{2}$

The result of auctions is somehow linked to the trading of bonds in the secondary market. The secondary market evolution is likely to represent the information set on which bidders base their offers at the auction. However, the secondary market evolution is not exogenous with respect to auctions. Previous research suggests that auctions are events that influence the secondary market (Lou et al., 2013; Beetsma et al., 2014). Primary dealers are market-makers and/or the most-active players in the secondary market, the evolution of both markets is therefore endogenous with respect to each other. Moreover, primary dealers' bids are likely to depend also upon their absorbing capacity, liquidity, investment strategies, amount already held (inventory), orders received by customers, etc. Not to mention that the result of auctions may depend also upon the auction procedure itself (Goldreich, 2007).

Auctions are well advertised and anticipated events since the Treasury makes the auctions calendar known far in advance, but the specific features of each auction may be made known only a couple of days before it takes place (AFME, 2014). Generally speaking, there are two main auction types (AFME, 2014): competitive auctions (also said discriminatory auctions) and marginal auctions (also said uniform-price auctions). In both auction types, the maximum quantity offered but not the price is decided ex-ante; the price is the result of the auction. As for the quantity assigned in the end, some Treasuries can decide to withhold part of the amount announced. $^{3}$

It is to say that not all the auctions are the same. Indeed, it is possible to distinguish between auctions of new bonds and of already outstanding bonds (tap issuance). The former represent a true innovation in the market since a new security is issued and this is going to be the new reference bond for that maturity. Differently, the latter represent reopenings of bonds already outstanding, such auctions therefore imply only an increase of their quantity. The label on-the-run is usually assigned to the latest issued bond of a particular maturity, the others (previously issued) are said off-the-run. The on-the-run bond is usually the most liquid, alias traded, among the bonds with the same maturity; for a discussion of the relationship between liquidity

\footnotetext{
${ }^{2}$ Among the primary dealers allowed to participate to auctions of Italy's GBs there is a smaller group named Specialists which enjoy special privileges against the fulfilling of specific underwriting and market-making obligations (MEF, 2011). Their activity is constantly monitored by the Italian Treasury to check whether such institutions fulfill their obligations to maintain the Specialist status. Their main official privilege consists in their option to acquire further amounts (overall limited) of the bond just auctioned in so-called supplementary auctions; the price for these is the same resulting from the main auction (ordinary auction). As for their unofficial privileges, they represent a direct market counterpart for many operations run and contracts stipulated by the Treasury. The list of specialists includes all the major Italian banks as well as other major foreign financial institutions. From the 8th April 2013, the list of specialists includes twenty financial institutions; for the complete list, see MEF (2013b).

${ }^{3}$ In case of competitive auctions, each winning bidder pays the price it offered. Differently, in case of marginal auctions, all the winning bidders pay the same price said marginal price. These are the main auction methods used in the majority of advanced economies (AFME, 2014). As for the faculty to withhold part of the amount announced, the German Treasury has used it often; differently, the Italian Treasury has used it scarcely (Beetsma et al., 2014).
} 
and market value, see Krishnamurthy and Vissing-Jorgensen (2012).

\section{Hypotheses on primary dealers' behavior}

The most relevant empirical results about the relationship between the primary and secondary market are the auction cycle (A) and underpricing (B). The former, which is the more recent, consists in observing an increasing market yield before the auction and a decrease afterwards. The latter regards the evidence of auction prices lower than contemporaneous market quotes.

Lou et al. (2013) and Beetsma et al. (2014) support an explanation of the auction cycle based mainly on inventory adjustment of the primary dealers due to either limited risk-bearing capacity or profit-seeking trading strategies $(A-i)$, but they also suggest that limited investors' mobility plays a role $(A-i i)$.

Primary dealers are usually expected to participate and buy bonds at the auctions on a regular basis; this is often a condition for their authorization as primary dealer. Then, they bear a disincentive to not participate to auctions, to make unlikely bids, or to bid for small amounts. ${ }^{4}$ Irrespective of such disincentive, Lou et al. (2013) and Beetsma et al. (2014) affirm that their absorbing capacity is limited and that they need to manage the risk brought by the new securities acquired. ${ }^{5}$ In this regard, Lou et al. (2013) suggest that they sell part of their stock, or short-sell part of the amount that they are going to bid for, before the auction in order to limit the higher risk that they would bear otherwise or for profit-seeking strategies. This causes a downwards pressure on prices which explains the increasing yield observed before the auction. Once the auction is over, the price realigns itself to its previous (or non-auction driven) level; this thesis is supported also by the results in Fleming and Rosenberg (2007). Both Lou et al. (2013) and Beetsma et al. (2014) seem to place more emphasis on the limited risk-bearing capacity than on profit-seeking as a motivation to sell before the auctions. Furthermore, Beetsma et al. (2014) highlight that such explanation implies a stronger impact of auctions on market yields when primary dealers find it more costly to bear risks (to wit, when GBs interest rates are more volatile, etc); they find support for this with regard to volatility.

The same authors suggest that also end-investors' portfolio stickiness might contribute to the auction cycle (A-ii). The idea is that end-investors in GBs (to wit, those who are willing to hold the bonds up to their maturity) are unresponsive to transitory yield changes because many of them do not have the intention to engage in short-term arbitrage trades. Such passive behavior therefore allows the increased supply of bonds

\footnotetext{
${ }^{4}$ To wit, this is true both in the USA and in Italy, and particularly true for Specialists in Italy's GBs.

${ }^{5}$ It is to be aware that the absorbing capacity may be very variable over time. To wit, EA banks had a much higher absorbing capacity at the time of the long-term refinancing operations (LTRO) launched by the ECB in December 2011. It is known that much of the resources borrowed by banks ended in purchasing of GBs instead than easing financing to businesses. Furthermore, it is to be aware that such unconventional monetary policies have an effect on the yields of GBs through different channels (Szczerbowicz, 2012).
} 
Figure 1: Underpricing

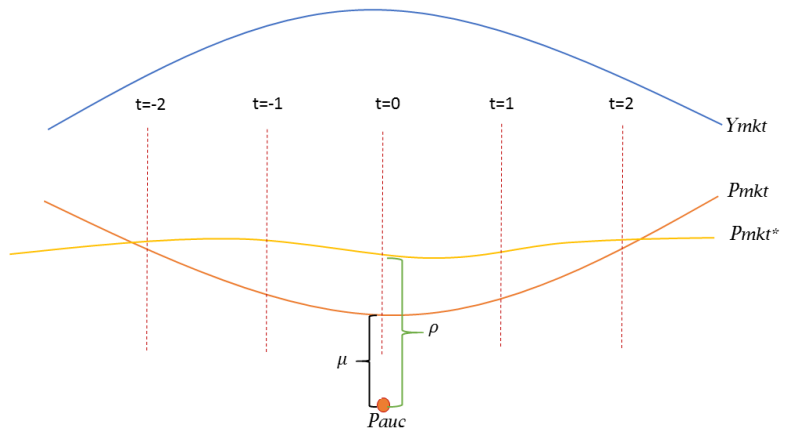

to shortly push the price downwards since a large number of debt holders do not change their portfolio over a short time span (4/5 days). Along this line, Beetsma et al. (2014) seek to assess whether the composition of holders (residents towards foreigners) makes any difference; domestic holders are known to be more passive. Based on a recent research of ours (Cafiso, 2014) and coherently with their results, we are keen to believe that it does not make much difference in the case of Italy.

Apart from the inventory-adjustment and end-investors' stickiness, also demand at the auction is likely to matter in terms of contemporaneous market evolution (A-iii). In this regard, a higher than expected primary dealers' demand is likely to push market yields downwards, while a lower one might cause the opposite. We will consider this explicitly through the bid-to-cover ratio.

As previously mentioned, underpricing is usually found when comparing the auction price (result of the auction) with contemporaneous market prices (Goldreich, 2007). Among other things, underpricing might depend also upon the design of the auction itself (Kremer and Nyborg, 2004; Keloharju et al., 2005; Jagannathan et al., 2014). Goldreich (2007) studies how the switch towards a different auction method of US Treasury securities has influenced underpricing. In this regard, results as the winner's curse suggest that a difference between prices is to expect anyway (Thaler, 1988). As for the amount of the difference, the auction cycle may play a role. Indeed, if it truly emerges, the market price at the auction day is below the level it would have been in case of no auction. Then, compared with an average of the market price around the auction day, the auction price would result even lower. Consider Figure 1 about this. From the Treasury perspective, this implies a higher cost with respect to the case when it could manage to place bonds at the current market price (amount $\mu$ in Figure 1), and even a higher cost if the Treasury managed to place the bonds at the market price that would be in case of no auction (amount $\rho$ in Figure 1).

On the whole, Lou et al. (2013) and Beetsma et al. (2014) seem to favor the explanation of the auction cycle based on the inventory adjustment due to limited risk-bearing capacity. Coherently, they provide a sound discussion of why it could be so. However, there is no direct test in their works. Indeed, this is a 
reasonable hypothesis, but hard to test directly. Without an insider knowledge of primary dealers' operations, their inventory adjustment is assumed from the overall market evolution. From this perspective, to affirm that they do it to contain risk is just another hypothesis very hard to check. We highlight this because we believe that the risk-reduction motivation behind the inventory adjustment requires caution. Indeed, as discussed by Gros (2013), the risk that banks assign to GBs has been particularly low, if not zero as in case of domestic bonds. ${ }^{6}$ This is coherent with the evidence that the EA banks' portfolio has been heavily loaded with domestic GBs at all times (Merler and Pisani-Ferry, 2012). Differently, the need for liquidity to use at the auction and/or profit-seeking trading strategies, as a motivation behind the inventory adjustment, do not soften what is usually perceived about the risk that banks assign to GBs particularly in no turmoil times. Perhaps, these are therefore a more sensible motivation for the inventory adjustment. Admittedly, also this hypothesis is hard to test.

\section{Data}

The secondary market considered in this paper is the MTS market, the spot market reserved to institutional investors property of the MTS group. This is a regulated market authorized by Italy's Ministry of Economics and Finance and constantly monitored by Banca d'Italia. All the secondary market data used in this paper are extracted consistently from this market. ${ }^{7}$

The first set of data used is made of data extracted from the MTS market by Banca d'Italia which transform and publish them. These are the yield series of the benchmark bond for specif bond categories defined by kind and maturity length. We consider: the 10-year BTP, the 5-year BTP, the 3-year BTP, and the CTZ (2-year); BTPs are coupon bonds (semiannual), CTZ are zero-coupon bonds. Among the bonds which belong to these categories, Banca d'Italia selects the benchmark one according to the following rule: "the benchmark security for each category is the last security issued from the time it becomes the most heavily traded security" (Banca d'Italia, 2014). Then, the benchmark changes from time to time when a new bond is issued and this meets the criterion. Even though the security at the basis of the series changes, the series is continuous and outliers do not emerge at the switching dates. Banca d'Italia converts the intraday-average clean price datum in terms of yield (redemption yield, or yield to maturity) by applying the formula in Appendix Ila. ${ }^{8}$

\footnotetext{
${ }^{6}$ This is because of regulatory guidelines on capital adequacy such as the Basel accords, or the Capital Requirements Directive within the Euro Area.

${ }^{7}$ The minimum amount for any transaction is $€ 2.5$ million. The MTS market is divided into two compartments, one for trading spot (MTS Cash) and one for those in repo (MTS Repo). MTS Cash is an interdealer market, operators can join conditional to the fulfilling of capital and professional minimum requirements. In both compartments an optional service of central counterparty, offered jointly by the Clearing and Guarantee SpA and LCH.Clearnet SA, is active.

${ }^{8}$ These series are publicly available. However, Banca d'Italia maintains confidentiality on which specific security turns out to be the benchmark. As for this, we obtained the ISIN code of the underlying benchmark security for the subperiod starting from
} 
The second group of data is made of the results of Treasury auctions. Auctions are executed by Banca d'Italia on behalf of the Italian Treasury, bidders make offers in terms of price. At the end of each auction, the price result of the auction is published; it is the same for all the winning bidders (marginal price) for the bonds considered in our analysis (BTP and CTZ). Also the auction yield is published, this derives from the auction price (plus the accrued interest) via the formula aforementioned (Appendix Ila). The auction price does not include the accrued interest (clean price), while the auction and the market yields include the accrued interest. Most importantly, the auction yield published reflects the yearly return gained by investors who keep the bonds until their maturity, but it does not reflect exactly the cost borne by the Treasury for the loan received. Indeed, the auction price, on which it is calculated, does not include the compensation paid to primary dealers as explained in section $5 .^{9}$

The third group of data is for a representative selection of 10-year BTPs. The price series of five bonds were kindly provided by the MTS staff, the time span is from the date the bond was issued until December 2014. The five bonds are: "IT0004019581", 10 auctions of this bond are observed in the period available (from February 23rd, 2006); "IT0004361041", 10 auctions available (from April 28th, 2008); "IT0004536949", 8 auctions available (from September 25th, 2009); "IT0004759673", 7 auctions available (from August 26th, 2011); "IT0004848831", 6 auctions available (from August 28th, 2012). The total number of auctions available for the pooled (across bonds) analysis is therefore 41 .

\section{Groups of auctions}

As said in section 2, the auction of a new bond of a given maturity makes the previous bond of the same maturity "off-the-run", while the new bond becomes the "on-the-run". Compared to off-the-run bonds, the on-the-run is somehow special: its liquidity is higher and it represents a better collateral for repo (Keane, 1996). The on-the-run bond may therefore have a higher price (Krishnamurthy and Vissing-Jorgensen, 2012), while the yield of the bond which loses its "on-the-run" status increases after the auction (Sundaresan, 1994). Consequently, we believe that it is important to distinguish across auctions of on-the-run and off-the-run bonds, as it will be proved true by the following analysis. We therefore apply a similar grouping to the auctions available in our dataset, but with an amendment in order to distinguish neatly between auctions of new bonds and auctions of bonds already outstanding. Indeed, market data on which to assess the auctions influence are

March 1st, 2010 onwards. From the analysis of this period, it emerges that: a new BTP 10y becomes the benchmark after 1 day (at $t=2$ ) in the majority of the cases available, this is also for a new BTP 5y and a new BTP 3y, a new CTZ becomes the benchmark after 2 day (at $t=3$ ) in the majority of the cases available. The on-the-run bond and the benchmark are the same from the day the new bond becomes the benchmark.

${ }^{9}$ In addition to the auction price and yield, other relevant information about the auction are published: max. amount offered, amount requested, amount assigned, number of bidders, etc. 
Table 1: Auction classification - groups A, B1, B2

\begin{tabular}{|c|c|}
\hline BTP 10-year & BTP 5-year \\
\hline $\begin{array}{l}\text { Total number of auctions: } 176 \\
\text { Number of auction days: } 166^{*} \\
* 10 \text { days with auctions of two different } \\
\text { bonds }\end{array}$ & $\begin{array}{l}\text { Total number of auctions: } 142 \\
\text { Number of auction days: } 138^{*} \\
* 4 \text { days with auctions of two different } \\
\text { bonds }\end{array}$ \\
\hline $\begin{array}{l}\text { Group-A auctions: } 22 \\
\text { Tot amount allotted: } 92250 € \mathrm{mln}\end{array}$ & $\begin{array}{l}\text { Group-A auctions: } 26 \\
\text { Tot amount allotted: } 102017 € \mathrm{mln}\end{array}$ \\
\hline $\begin{array}{l}\text { Group-B.1 auctions: } 126 \\
\text { Tot amount allotted: } 345196 € \mathrm{mln}\end{array}$ & $\begin{array}{l}\text { Group-B.1 auctions: } 109 \\
\text { Tot amount allotted: } 287489 € \mathrm{mln}\end{array}$ \\
\hline $\begin{array}{l}\text { Group B.2 auctions: } 28 \\
\text { Tot amount allotted: } 32080 € \mathrm{mln}\end{array}$ & $\begin{array}{l}\text { Group B.2 auctions: } 7 \\
\text { Tot amount allotted: } 5445 € \mathrm{mln}\end{array}$ \\
\hline BTP 3-year & CTZ (2-year) \\
\hline $\begin{array}{l}\text { Total number of auctions: } 164 \\
\text { Number of auction days: } 163^{*} \\
* 1 \text { day with auctions of two different } \\
\text { bonds }\end{array}$ & $\begin{array}{l}\text { Total number of auctions: } 158 \\
\text { Number of auction days: } 158^{*} \\
*^{0} \text { day with auctions of two different } \\
\text { bonds }\end{array}$ \\
\hline $\begin{array}{l}\text { Group-A auctions: } 33 \\
\text { Tot amount allotted: } 129460 € \mathrm{mln}\end{array}$ & $\begin{array}{l}\text { Group-A auctions: } 31 \\
\text { Tot amount allotted: } 107937 € \mathrm{mln}\end{array}$ \\
\hline $\begin{array}{l}\text { Group-B.1 auctions: } 129 \\
\text { Tot amount allotted: } 338911 € \mathrm{mln}\end{array}$ & $\begin{array}{l}\text { Group-B.1 auctions: } 127 \\
\text { Tot amount allotted: } 284297 € \mathrm{mln}\end{array}$ \\
\hline $\begin{array}{l}\text { Group B.2 auctions: } 2 \\
\text { Tot amount allotted: } 2779 € \mathrm{mln}\end{array}$ & $\begin{array}{l}\text { Group B. } 2 \text { auctions: } 0 \\
\text { Tot amount allotted: } € \mathrm{mln}\end{array}$ \\
\hline
\end{tabular}

available only for bonds already traded. Accordingly, the following groups of auctions are defined:

A) Auctions of new bonds (first tranche of the series, $\mathrm{nT}=1$ ).

B) Auctions of bonds already outstanding (tranche auctioned greater than one, $\mathrm{nT}>=3$ ).

B.1) Further auctions of the most recent, alias, of the "on-the-run bond".

B.2) Auctions of "off-the-run" bonds. ${ }^{10}$

Group-A auctions represent true innovations in the market and therefore determine a switch of the onthe-run bond towards the one just auctioned (to which a new ISIN code is assigned). Group-B.1 auctions imply an increase of the amount outstanding of the on-the-run bond. Group-B.2 auctions increase the amount outstanding of off-the-run bonds. The number of auctions by group in our data set is in Table 1, and plotted in Figure 2 for further consideration.

Figure 2 shows that the Italian Treasury changed partly its issuing policy during the period of the financial crisis (June 2008 - August 2009) and of the Euro Area debt crisis (July 2011 - January 2013). With regard to the 10-year BTP, it often issued off-the-run bonds in those periods, a practice which does not emerge in normal times. Likely, there was some convenience behind this innovation since the choice of the maturity (or

\footnotetext{
${ }^{10}$ Subsequent auctions of the same bond are identified by the number of the tranche auctioned. Even numbers are for limited reopenings reserved to specialists; the price for these is the same from the auction of the previous odds-numbered tranche. Apart from the amount outstanding, these do not provide any new information, we therefore disregard them in the current analysis.
} 
Figure 2: Auctions by group
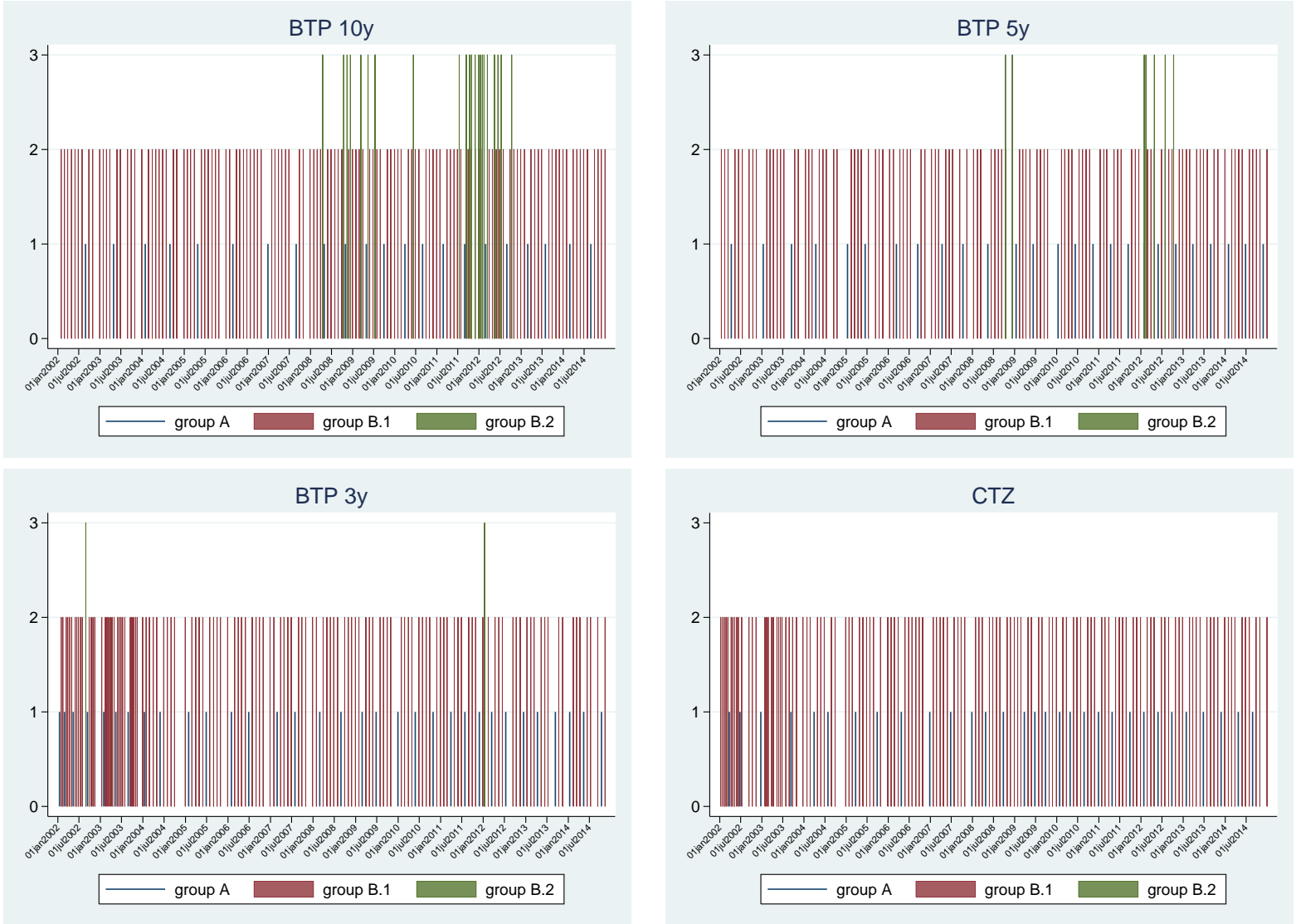

residual life) of the bonds to issue is an outcome of the Treasury's strategy to manage its debt (Dottori and Manna, 2015). Once the turmoil was over, the Treasury returned to the habit of issuing just on-the-run bonds.

\section{The influence of auctions on the secondary market}

Auctions are events in the primary market, but it is reasonable that they influence the secondary market for what discussed in section 2. Accordingly, Fleming and Rosenberg (2007), Lou et al. (2013) and Beetsma et al. (2014) speak of an auction cycle to refer to the evolution of the secondary market when auctions occur. The auction cycle consists in an increase of the market yield during the days preceding the auction, with a local maximum at the day of the auction, and in a decrease afterward.

Admittedly, such supposed regularity is somehow surprising because it might leave room to arbitrage gains. In this section we aim to gain more information about the evolution of the market yield over the days around auctions. More in details, we aim to verify whether such auction cycle emerges in our data, to check whether it is a widespread pattern, the time span it covers, and to study at which extent it depends upon the volatility in the market. For the analysis in this section we use the data on the market yield of the benchmark bond 
(first group of data in section 3). A robustness check of the results is developed in the last subsection by using the data for the five 10-year BTPs obtained by MTS (third group of data in section 3).

\subsection{Auction cycles}

To study the influence of auctions on the secondary market, we start by considering a window centered at the auction day and check how the market yield of the benchmark bond (MRY, hereinafter) evolves within such window in the manner of Lou et al. (2013). We consider a 9-day wide window, such width is optimal because it avoids overlaps since some auctions are less than two weeks away from one another. Then, the analysis is developed by using the Dif 1 variable: Dif $1_{t}=M R Y_{t}-M R Y_{0}$ where $t=-4, \ldots, 4$ and $t=0$ is the auction day. We consider only group-B1 auctions for the analysis of the auction cycle, this is to ensure that the auctions considered are of the benchmark bond at the basis of the MRY series. To wit, we study the influence of further auctions of bond $\mathrm{X}$ (on-the-run) on the market yield of the same bond $\mathrm{X} .{ }^{11}$

The graphs for the GBs considered are in Figure 3, the values plotted are in the Table 11 for the 10-year BTP, in Table 12 for the 5-year BTP, in Table 13 for the 3-year BTP, in Table 14 for the CTZ; all these tables are in Appendix I. The values plotted are the by-day average of Dif $1_{t}$ across all the auctions in the period January 2002 - December 2014. Also our data confirm on-average the auction cycle as in Lou et al. (2013) (who consider US data) and in Beetsma et al. (2014) (who consider Italy and Germany), this has an inverted V-shaped pattern. ${ }^{12}$

As said, the V-shaped pattern emerging from the graphs in Figure 3 is the result of the by-day average across all the auctions. However, eyeballing auction-by-auction graphs suggests that such pattern is often missed; the graphs for each auction are in Appendix Ilb. With the scope to get information on how much the auction cycle pattern is really shared across different auctions, we count the auctions where the market yield exhibits an evolution consistent with the auction cycle through first differences: $\triangle M R Y_{t}=M R Y_{t}-M R Y_{t-1}$ where $t=0$ is the auction day. The inverted $\mathrm{V}$-shaped pattern requires positive MRY variations up to the auction day and negative variations afterwards. Then, the first check (ckA1) consists in counting the number of auctions where $\triangle M R Y_{0}>0$ over the total (to wit, when a MRY increase is observed at the auction day). The second check $(c k A 2)$ requires to meet two conditions jointly: $\triangle M R Y_{0}>0 \& \triangle M R Y_{1}<0$; this latter

\footnotetext{
${ }^{11}$ Indeed, the benchmark is the newest bond from the moment it becomes the most traded. This cannot be for group-A auctions, since at the auction day these are not even officially traded in the MTS market (they are in the grey market). Based on the five 10-year BTPs obtained from MTS, it emerges that their official trading starts the day after the auction.

${ }^{12}$ In this regard, it is also of interest to check whether auctions of bonds which are not the benchmark have an effect on the trading of the benchmark, this can be done by drafting the auction cycle graphs for group-B2 auctions. Given the limited number of group-B2 auctions as reported in Table 1, we do this only for the 10-year BTP. The auction cycle graph is in Figure 7 in Appendix I. In this case, a local maximum at the auction day emerges too, but the dynamics is much less smooth, probably because of the limited number of observations (to wit, for the 10y BTP, 18 obs in Figure 5 against the 128 obs in Figure 7).
} 
Figure 3: Auction cycle graphs, group-B1 auctions
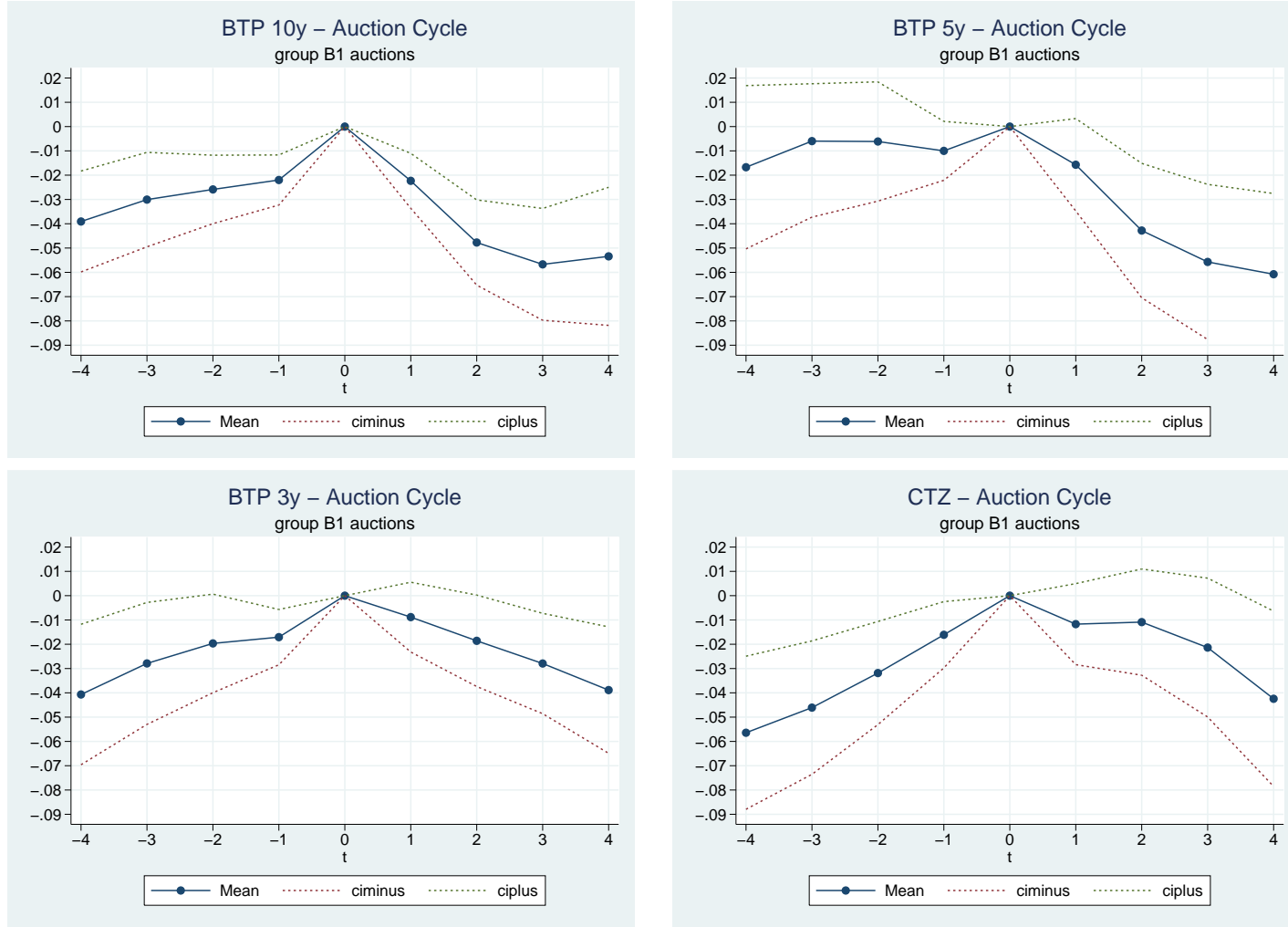

Figure 4: time axis

\begin{tabular}{|c|c|c|c|c|}
\hline & $\Delta M R Y_{-1}$ & $\Delta M R Y_{0}$ & $\Delta M R Y_{1}$ & $\Delta M R Y_{2}$ \\
\hline For cons sisency with the auction cocle & + & + & - & - \\
\hline$M R Y_{-2}$ & $M R Y_{-1}$ & $M R Y_{0}$ & $M R Y_{1}$ & $M R Y_{2}$ \\
\hline$t=$ & 1 & 1 & 1 & 1 \\
\hline-2 & -1 & 0 & 1 & 2 \\
\hline
\end{tabular}

implies a MRY decrease the day after. The third check $(c k B 2)$ requires to meet four conditions jointly: the first two are the ones for $(c k A 2)$ plus $\triangle M R Y_{-1}>0 \& \triangle M R Y_{2}<0$. This is as measuring the cycle-width across the auctions (distribution). The ordering of $\triangle M R Y_{t}$ is displayed in Figure 4. $\triangle M R Y_{t}$ values below the 10th percentile of their own distribution are ruled out from this exercise in order to avoid considering marginal observations. We report the result of these checks in Table 2.

A MRY increase at the auction day is observed in the largest part of observations available (65.7\%-76.5\%). Although, such increase is followed by a negative variation in a much lower number of cases (from $28.2 \%$ to $51.3 \%$ ); only for the 10-year BTP this is around half of the observations available. Furthermore, an evolution consistent with the auction cycle covering 4 days is only in very few cases $(7.7 \%-19.1 \%)$. Interestingly, a dynamics less consistent with the auction cycle emerges from shorter maturity bonds. The conclusion is that apart from the increase at the auction day, the auction cycle shown in Figure 3 is more a result of aggregation than a widespread pattern. This finding challenges the conclusions in Lou et al. (2013) and Beetsma et al. 
Table 2: Check of the Auction cycle width

\begin{tabular}{c|c}
\hline BTP $10 y$ & BTP 5y \\
\hline group-B.1 $\rightarrow 115$ days of 126 & group-B.1 $\rightarrow 99$ days of 109 \\
ckA1 $=88(76.5 \%) ;$ & ckA1 $=67(67.7 \%) ;$ \\
ckA2 $=59(51.3 \%)$ & ckA2 $=36(36.7 \%) ;$ \\
ckB2 $=22(19.1 \%)$ & ckB2=15 $(15.1 \%)$ \\
\hline BTP 3y & CTZ $(2 y)$ \\
\hline group-B.1 $\rightarrow 122$ days of 129 & group-B.1 $\rightarrow 117$ days of 127 \\
ckA1 $=85(70.0 \%) ;$ & ckA1 $=77(65.7 \%) ;$ \\
ckA2 $=43(35.2 \%) ;$ & ckA2 $=33(28.2 \%) ;$ \\
ckB2 $=18(14.7 \%)$ & ckB2=9(7.7\%)
\end{tabular}

(2014) about the relevance of the auction cycle.

The controversial finding just discussed calls for a further analysis of the MRY evolution when Treasury auctions occur, this is now developed through a pure autoregressive $\operatorname{ARMA}(p, q)$ model for the variation of the Market Redemption Yield $\left(\triangle M R Y_{t}\right) .{ }^{13}$ This model is functional to check whether the auction days are significant outliers in the MRY series and whether or not the auction cycle emerges in this framework too. The model is specified in first differences coherently with the previous analysis:

$$
\triangle M R Y_{t}=\alpha+\sum_{p=1}^{P} \beta_{p} \cdot \triangle M R Y_{t-p}+\sum_{q=0}^{Q} \gamma_{q} \cdot \epsilon_{t-q}+d A u_{t}
$$

Based on the Box and Jenkins' approach (Enders, 2009), we compared several alternative specifications of eq.1 ( $p$ and $q$ varying from 0 to 5 ) in order to identify the most efficient. This turned to be an $\operatorname{ARMA}(4,3)$ for the 10-year BTP series, an $\operatorname{ARMA}(3,2)$ for the 5-year BTP series, an $\operatorname{ARMA}(2,2)$ for the 3-year BTP series, an $\operatorname{ARMA}(3,2)$ for the CTZ series. ${ }^{14}$

Once identified the most suited model, we perform three estimations for each bond by including dummies which control for the auctions. As before, we focus primarily on group-B1 auctions, but we can also consider group-A auctions in this framework in order to assess how market innovations affect the MRY series. Defined $t=0$ any auction day, the dummies are constructed as follows. The first estimation $(\mathrm{A})$ includes a dummy only for the auction day of group-B1 auctions: $d A u \cdot B 1.0_{t}$ which is equal to 1 if $t=0,0$ otherwise. The second estimation (B) regards again group-B1 auctions, but it includes dummies for the days around the auction as well: $d A u \cdot B 1.0_{t}$ as in estimation $\mathrm{A}, d A u \cdot B 1.1_{t}$ equal to 1 when $t=1$ and 0 otherwise, $d A u \cdot B 1.2_{t}$ equal to 1 when $t=2$ and 0 otherwise, $d A u . B 1 . m 1_{t}$ equal to 1 when $t=-1$. The third estimation (C) is for group-A

\footnotetext{
${ }^{13}$ Differently from Beetsma et al. (2014), we opt for an $\operatorname{ARMA}(p, q)$ approach to ground the estimation on established econometric techniques. First differences are also functional to shelter the analysis from possible non-stationarity.

${ }^{14}$ The most efficient specification was selected on the basis of the minimization of the Bayesian Information Criterion and the rejection of the portmanteau test of white noise (Ljung and Box's Q-test, Enders 2009); the alternatives did not include $d A U_{t}$ at this step. Estimations are performed via the maximum-likelihood method and Huber-White standard-errors are instructed.
} 
Table 3: ARMA for $\triangle M Y_{t}$ : BTP 10y \& BTP 5y

\begin{tabular}{|c|c|c|c|c|c|c|c|}
\hline \multicolumn{4}{|c|}{ BTP 10y, ARMA $(4,3)$} & \multicolumn{4}{|c|}{ BTP 5y, ARMA(3,2) } \\
\hline mry10Ybtp & A & $\mathrm{B}$ & C & mry5Ybtp & $A$ & B & C \\
\hline$d A u \cdot B 1.0_{t}$ & $0.024 * *$ & $0.023 * *$ & & $d A u . B 1.0_{t}$ & $0.012 * *$ & $0.011^{*}$ & \\
\hline$d A u \cdot B 1.1_{t}$ & & $-0.021^{* *}$ & & $d A u . B 1.1_{t}$ & & -0.014 & \\
\hline$d A u \cdot B 1 . m 1_{t}$ & & 0.004 & & $d A u . B 1 . m 1_{t}$ & & -0.004 & \\
\hline$d A u \cdot B 1.2_{t}$ & & $-0.023^{* *}$ & & $d A u . B 1.2_{t}$ & & $-0.023^{* *}$ & \\
\hline$d A u \cdot A \cdot 0_{t}$ & & & $0.047^{* *}$ & $d A u \cdot A .0_{t}$ & & & $0.055^{* *}$ \\
\hline cons & $-0.002^{*}$ & 0.000 & -0.001 & cons & -0.001 & 0.000 & -0.002 \\
\hline ARMA & & & & ARMA & & & \\
\hline L.ar & $0.943 * *$ & $0.969 * *$ & $0.959 * *$ & L.ar & $1.864 * *$ & $1.868 * *$ & $1.860 * *$ \\
\hline L2.ar & $0.610^{* *}$ & $0.617^{* *}$ & $0.611^{* *}$ & L2.ar & $-1.163^{* *}$ & $-1.163^{* *}$ & $-1.157^{* *}$ \\
\hline L3.ar & $-0.928 * *$ & $-0.942 * *$ & $-0.934 * *$ & L3.ar & $0.167^{* *}$ & $0.167^{* *}$ & $0.164^{* *}$ \\
\hline L4.ar & $0.151^{* *}$ & $0.152 * *$ & $0.153^{* *}$ & L.ma & $-1.720 * *$ & $-1.727^{* *}$ & $-1.719 * *$ \\
\hline L.ma & $-0.829 * *$ & $-0.860 * *$ & $-0.850 * *$ & L2.ma & $0.851^{* *}$ & $0.855^{* *}$ & $0.851^{* *}$ \\
\hline L2.ma & $-0.732 * *$ & $-0.736 * *$ & $-0.732 * *$ & & & & \\
\hline L3.ma & $0.784^{* *}$ & $0.804^{* *}$ & $0.795^{* *}$ & & & & \\
\hline cons & $0.060 * *$ & $0.060 * *$ & $0.060 * *$ & cons & $0.075^{* *}$ & $0.075^{* *}$ & $0.075^{* *}$ \\
\hline aic & -9222.245 & -9245.84 & -9215.21 & aic & -7689.061 & -7696.02 & -7700.26 \\
\hline bic & -9161.207 & -9166.49 & -9154.172 & bic & -7640.23 & -7628.88 & -7651.43 \\
\hline $\mathrm{N}$ & 3307 & 3307 & 3307 & $\mathrm{~N}$ & 3307 & 3307 & 3307 \\
\hline \multicolumn{4}{|c|}{$\begin{array}{l}\text { Notes: The portmanteau test does not reject } \\
\text { "H0:residuals are White-Noise" at the selected lag-order } \\
\text { and up to } 12 \text { lags. }\end{array}$} & \multicolumn{4}{|c|}{$\begin{array}{l}\text { Notes: The portmanteau test does not reject } \\
\text { "H0:residuals are White-Noise" at the selected lag-order } \\
\text { and up to } 6 \text { lags. }\end{array}$} \\
\hline
\end{tabular}

auctions: $d A u \cdot A .0_{t}$ equal to 1 for group-A auctions when $t=0$ and 0 otherwise. The benchmark changes at $t=2$, this last estimation is therefore not biased by the switch. For the intuition behind the timing of the dummies, consider again Figure 4. The estimation output is in Table 3 for the 10-year BTP and for the 5-year BTP, and in Table 4 for the 3-year BTP and the CTZ.

The estimations in column $A$ in Table 3 and 4 show a significant positive effect of auctions on the MRY as suggested by the auction cycle literature: auction days are associated with MRY positive variations $\left(d A u . B 1.0_{t}\right)$. To appreciate the magnitude of the estimated coefficients, we refer to the quantiles of the distribution of $\triangle M R Y$ taken in absolute values (Table 10 in Appendix I). ${ }^{15}$ The estimations in columns $\mathrm{B}$ in Table 3 and 4 provide coefficients for the dummies around the auction day which are signed consistently with the prescription of the auction cycle in the majority of the cases. However, very few are significant (mainly for the 10 -year BTP), this undermines the relevance of the auction cycle. ${ }^{16}$ On the whole, the output of these estimations is coherent with the result of the descriptive analysis previously discussed, particularly with regard

\footnotetext{
${ }^{15}$ The coefficient for the 10 -year BTP signals a $2.4 \mathrm{bp}$ variation which is close to the 50th-pc of its abs $(\triangle M R Y)$ distribution, it is $1.2 \mathrm{bp}$ for the 5 -year BTP (below the 25th-pc), and $1.9 \mathrm{bp}$ for the 3-year BTP (between the 25th and the 50th-pc), and 1.8 bp for the CTZ (between the 25th and the 50th-pc).

${ }^{16}$ Not surprisingly, a proper Likelihood-Ratio test of equality across the dummies reject the null for all the four bonds considered. LR test for the restricted versus unrestricted model; not reported, available upon request.
} 
Table 4: ARMA for $\triangle M Y_{t}$ : BTP 3y \& CTZ

\begin{tabular}{|c|c|c|c|c|c|c|c|}
\hline \multicolumn{4}{|c|}{ BTP 3y, ARMA(2,2) } & \multicolumn{4}{|c|}{ CTZ, ARMA $(3,2)$} \\
\hline mry3Ybtp & A & $\mathrm{B}$ & $\mathrm{C}$ & mry2Yctz & $A$ & B & C \\
\hline$d A u \cdot B 1.0_{t}$ & $0.019 * *$ & $0.018 * *$ & & $d A u \cdot B 1.0_{t}$ & $0.018 * *$ & $0.019 * *$ & \\
\hline$d A u \cdot B 1.1_{t}$ & & -0.007 & & $d A u . B 1.1_{t}$ & & -0.009 & \\
\hline$d A u . B 1 . m 1_{t}$ & & 0.003 & & $d A u \cdot B 1 . m 1_{t}$ & & $0.017^{* *}$ & \\
\hline$d A u . B 1.2_{t}$ & & -0.008 & & $d A u . B 1.2_{t}$ & & 0.003 & \\
\hline$d A u \cdot A \cdot 0_{t}$ & & & $0.046 * *$ & $d A u \cdot A \cdot 0_{t}$ & & & $0.038 * *$ \\
\hline cons & -0.002 & -0.001 & -0.001 & cons & -0.002 & -0.002 & -0.002 \\
\hline ARMA & & & & ARMA & & & \\
\hline L.ar & $0.573^{* *}$ & $0.573^{* *}$ & 1.15 & L.ar & $1.893^{* *}$ & $1.896 * *$ & $1.890 * *$ \\
\hline L2.ar & $-0.923 * *$ & $-0.924 * *$ & -0.525 & L2.ar & $-1.166^{* *}$ & $-1.167^{* *}$ & $-1.164 * *$ \\
\hline L.ma & $-0.511^{* *}$ & $-0.512 * *$ & -1.087 & L3.ar & $0.161^{* *}$ & $0.161^{* *}$ & $0.160^{* *}$ \\
\hline \multirow[t]{2}{*}{ L2.ma } & $0.913^{* *}$ & $0.914^{* *}$ & 0.42 & L.ma & $-1.775^{* *}$ & $-1.778^{* *}$ & $-1.772^{* *}$ \\
\hline & & & & L2.ma & $0.891^{* *}$ & $0.892^{* *}$ & $0.889 * *$ \\
\hline aic & -6773.71 & -6769.62 & -6741.772 & aic & -6680.715 & -6681.1 & -6680.637 \\
\hline bic & -6730.983 & -6708.58 & -6699.046 & bic & -6632.043 & -6614.18 & -6631.965 \\
\hline $\mathrm{N}$ & 3307 & 3307 & 3307 & $\mathrm{~N}$ & 3242 & 3242 & 3242 \\
\hline \multicolumn{4}{|c|}{$\begin{array}{l}\text { Notes: The portmanteau test does not reject } \\
\text { "H0:residuals are White-Noise" at the selected } \\
\text { lag-order. }\end{array}$} & \multicolumn{4}{|c|}{$\begin{array}{l}\text { Notes: The portmanteau test does not reject } \\
\text { "H0:residuals are White-Noise" at the selected lag-order } \\
\text { and up to } 9 \text { lags. }\end{array}$} \\
\hline
\end{tabular}

to the limited width of the auction cycle. ${ }^{17}$

The estimations in columns $\mathrm{C}$ in Table 3 and 4 report higher coefficients in case of group- $\mathrm{A}$ auctions $\left(d A u \cdot A \cdot 0_{t}\right)$. This means that auctions of a new bond $\mathrm{Y}$ have a deeper effect on the MRY of bond $\mathrm{X}$ than auctions of the bond $\mathrm{X}$ itself.

\subsection{The influence of auctions with respect to volatility}

Beetsma et al. (2014) study the link between the effect of auctions and volatility. They find interesting results suggesting that the auction cycle is stronger during the crisis period, when yield volatility and CDS spreads are larger. This is in line with the inventory-adjustment explanation of the auction cycle due to limited risk-bearing capacity which they support. To wit, when risk is higher, primary dealers sell or shot-sell more bonds before the auction and this implies a deeper auction cycle. Their estimations provide evidence in support of this thesis.

We too are interested in studying whether the influence of auctions is conditioned by volatility. Indeed, apart from the relevance of the result per sè, this could suggest to the Treasury to adopt a different issuing policy at times of turmoil. We develop a very different analysis than Beestma et al.'s (2014) to investigate this issue. We prefer a non linear approach based on Markov-switching estimations where the number of significant

\footnotetext{
${ }^{17}$ We underline that the results about the $d A U_{t}$ dummies do not change significantly for different specifications of the $\operatorname{ARMA}(p, q)$ model.
} 
Figure 5: Auction Cycle graphs by volatility layer
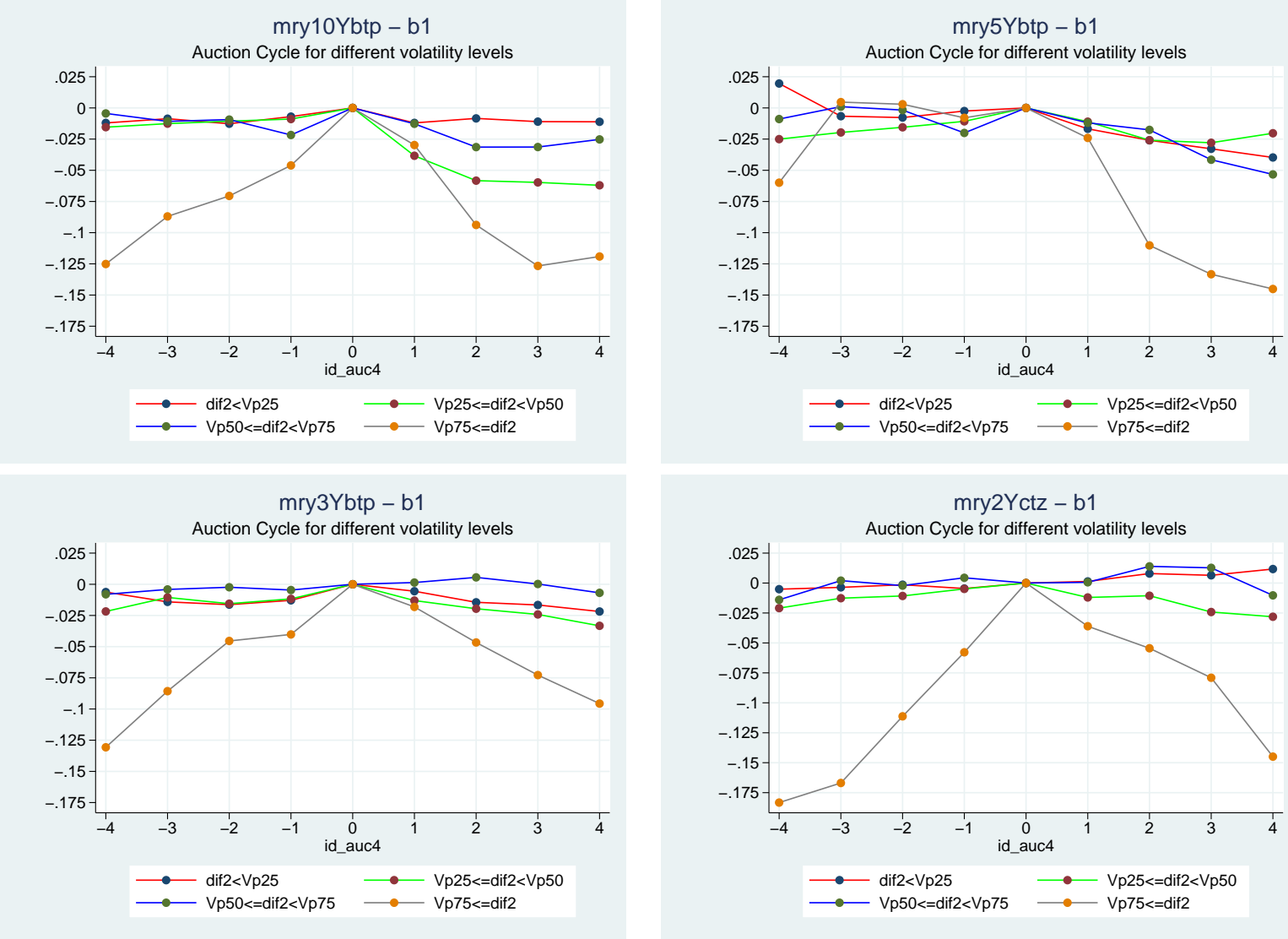

regimes is detected through an ex-ante exploratory analysis. To start, each auction is assigned to one of four volatility layers and auction cycle graphs are plotted for each layer in Figure 5. ${ }^{18}$

The plots in Figure 5 show that for the fist three layers there is not much difference in the depth of the auction cycle. Differently, the depth of the auction cycle is much more for the highest volatility layer (above the 75th percentile). Apart from the plots, this emerges from the values in the Tables 11, 12, 13, 14 in Appendix I as well. ${ }^{19}$ Eventually, we assume only two significant levels of volatility and that these represent different regimes as for the influence of auctions on the secondary market dynamics.

\footnotetext{
${ }^{18}$ We use historical volatility calculated as the standard deviation of the MRY over the 5 days preceding the auction (auction day included). Then, a certain volatility value is assigned to each auction day. After that, we consider the distribution of the volatility values by looking at the auction days altogether and define four volatility layers: 1) below the 25th percentile, 2) between the 25th and the 50th percentile, 3) between the 50th and the 75th percentile, 4) above the 75th percentile. Eventually, each auction is assigned to a layer according to its volatility value. Subsequently, we calculate $D i f 1_{t}$ for each day within the 9 -day window centered at the auction day, and average the $D$ if $1_{t}$ values across the auctions within the same volatility layer. The values of Dif $1_{t}$ by day and volatility layer are plotted in Figure 5 and reported in Table 11 for the 10-year BTP, in Table 12 for the 5-year BTP, in Table 13 for the 3-year BTP, and in Table 14 for the CTZ (Appendix I).

${ }^{19}$ The bottom rows "sum" and "sumABS" in Table 11, 12, 13, 14 report the sum of all Dif $1_{t}$ values within the 9-day window.sum considers the Dif $1_{t}$ values observed (to wit, signed as reported in the by-day rows of each Table), while sumABS reports the sum of the by-day $D i f 1_{t}$ taken in absolute values; these two differ only in few cases since just few $D i f 1_{t}$ values are positive. The values in these rows show much higher figures for the highest volatility layer with respect to the other three for which the difference seems negligible. We also checked the case when 5 volatility layers are instructed. In this case, a more marked difference between the highest layer and all the others emerge. Indeed, the more layers are considered, the larger the difference gets.
} 
Consequentially, an analysis aimed to study the effect of auctions at different volatility levels can be performed through Markov-switching estimations (Hamilton, 2008). ${ }^{20}$ We estimate one model for each of the four GBs considered by instructing two regimes $(N=2)$ according to what emerges from the graphs in Figure 5. The AR specification is taken from the estimations in Tables 3 and 4; the MA components are not included in the MS estimations. Then, the representation of the AR models used is similar to the one in eq. 1 :

$$
\triangle M R Y_{t}=\alpha^{n}+\lambda^{n} \cdot d A u_{t}+\sum_{p=1}^{P} \beta_{p} \cdot \triangle M R Y_{t-p}+\epsilon_{t},
$$

where the $n$-superscripts mark the regime-switching coefficients. The variable of interest is the auction dummy $d A u_{t}$, the scope of the estimations is to estimate the $\lambda^{n}$ coefficients for $n=1,2$ and check their difference. We consider only group-B1 auctions at the auction day, then $d A u_{t}=i d A u \cdot B 1.0_{t}$. We estimate a variation of the standard framework à la Filardo (1994) where transition probabilities are based not just on the evolution of the dependent variable but also on the 5-day historical volatility. ${ }^{21}$ The estimation output for the 10-year and 5-year BTPs is in Table 5, for the 3-year BTP and the CTZ is in Table 6; the plots of the smoothed regime probabilities for the estimations in Table 5 and 6 are respectively in Figure 8 and 9 in Appendix I.

As for the 10-year BTP, the estimation output suggests a significant effect of the auctions in both regimes, but this is much higher in the high volatility regime (2); however, still coherently below the maximum reported in Table 10. A Wald test on the equality of $d A u . B 1.0_{t}$ across the two regimes rejects the null $\left(\chi^{2}=50.63\right.$, p.value $=0.000)$. The estimation output therefore produces what expected if one believes that auctions have a deeper influence on market quotes at times of higher volatility. Also for the 5-year BTP the $d A u \cdot B 1.0_{t}$ coefficient is higher in the high volatility regime (2), but it is statistically significant only in the low-volatility regime (1); the Wald test on the equality of $d A u . B 1.0_{t}$ does not reject the null $\left(\chi^{2}=1.833\right.$, p.value $\left.=0.175\right)$. Same results for the 3-year BTP where regime 1 is the high volatility one, the Wald test does not reject the null for this bond too $\left(\chi^{2}=0.750, p\right.$.value $\left.=0.386\right)$. In case of the CTZ the output is as for the 10-year BTP: significant in both regimes, but larger effect in the high volatility one (regime 1); the Wald test rejects the null $\left(\chi^{2}=270.37\right.$, p.value $\left.=0.000\right)$.

On the whole, the 10-year BTP and the CTZ provide clearer evidence in favor of a deeper influence of

\footnotetext{
${ }^{20}$ Markov switching estimations split endogenously the data sample into $N$ (equal or greater than 2 ) groups, alias regimes, where the variables of interest are assumed to behave differently under the $N$ regimes.

${ }^{21}$ Central to this approach is the concept of transition probabilities modeled trough a Markov-Chain process (FrühwirthSchnatter, 2006). Transition probabilities quantify the probability to switch from one regime to the others and, in the standard formulation, these are constant and defined on the dependent variable. As said, we estimate a variation of the standard framework à la Filardo (1994) where transition probabilities are based not just on the evolution of the dependent variable, but also on another variable. The external variable which we board in is the 5-day historical volatility as previously used; this is done with the scope to define the regimes with respect to volatility.
} 
Table 5: MS-AR for $\triangle M Y_{t}$ : BTP 10y \& BTP 5y

\begin{tabular}{|c|c|c|c|c|c|}
\hline \multicolumn{3}{|c|}{ BTP 10-year, MS-AR(4) } & \multicolumn{3}{|c|}{ BTP 5-year, MS-AR(3) } \\
\hline$i d A u . B 1.0_{t}$ & $0.015^{* * *}$ & $0.461 * * *$ & \multirow{2}{*}{$\begin{array}{l}d A u \cdot B 1.0_{t} \\
\alpha\end{array}$} & $\frac{\text { regime } 1}{0.013^{*}}$ & $\frac{\text { regime } 2: \mathrm{HV}}{0.204}$ \\
\hline \multirow[t]{2}{*}{$\alpha$} & 0.001 & $-0.228 * * *$ & & 0.001 & $-0.383 * * *$ \\
\hline & common & & & common & \\
\hline L2.ar & $0.046 * * *$ & & L2.ar & $-0.050 * * *$ & \\
\hline L3.ar & $-0.037 * * *$ & & L3.ar & $-0.054 * * *$ & \\
\hline L4.ar & $-0.022 * * *$ & & & & \\
\hline $\log (\operatorname{sigma})$ & $-2.929 * * *$ & & $\log (\operatorname{sigma})$ & $-2.697^{* * *}$ & \\
\hline \multicolumn{3}{|c|}{$\begin{array}{l}\text { Notes: i) The regime regressors are } \alpha \text { and lagged } \\
\text { volatility, ii) Regime } 2 \text { is the high-volatility one. iii) The } \\
\text { test of "H0: } r g 1 . i d A u . B 1.0_{t}=r g 2 . i d A u . B 1.0_{t} \text { " yields } \\
\chi^{2}=50.63(\text { p.value }=0.000) .\end{array}$} & \multicolumn{3}{|c|}{$\begin{array}{l}\text { Notes: i) The regime regressors are } \alpha \text { and lagged } \\
\text { volatility, ii) Regime } 2 \text { is the high-volatility one. iii) The } \\
\text { test of "H0: } r g 1 . i d A u . B 1.0_{t}=r g 2 . i d A u . B 1.0_{t} \text { " yields } \\
\left.\chi^{2}=1.833 \text { (p.value }=0.175\right) .\end{array}$} \\
\hline
\end{tabular}

Table 6: MS-AR for $\triangle M Y_{t}$ : BTP 3y \& CTZ

\begin{tabular}{|c|c|c|c|c|c|}
\hline \multicolumn{3}{|c|}{ BTP 3-year, MS-AR(2) } & \multicolumn{3}{|c|}{ CTZ, MS-AR(3) } \\
\hline \multirow[b]{2}{*}{$d A u \cdot B 1.0_{t}$} & regime $1: \mathrm{HV}$ & regime 2 & \multirow[b]{2}{*}{$d A u . B 1.0_{t}$} & \multicolumn{2}{|c|}{ regime $1: \mathrm{HV} \quad$ regime 2} \\
\hline & 0.078 & $0.017^{* *}$ & & $0.731^{* * *}$ & 0.005 \\
\hline \multirow[t]{2}{*}{$\alpha$} & $-0.460 * * *$ & 0.003 & $\alpha$ & $-0.430 * * *$ & $0.003^{*}$ \\
\hline & \multicolumn{2}{|l|}{ common } & & \multicolumn{2}{|l|}{ common } \\
\hline L.ar & \multicolumn{2}{|l|}{$0.230 * * *$} & L.ar & \multicolumn{2}{|l|}{$0.279 * * *$} \\
\hline \multirow[t]{2}{*}{ L2.ar } & \multicolumn{2}{|l|}{0.012} & L2.ar & \multicolumn{2}{|l|}{$-0.038 * * *$} \\
\hline & & & L3.ar & \multicolumn{2}{|l|}{$0.026 * * *$} \\
\hline $\log ($ sigma $)$ & \multicolumn{2}{|l|}{$-2.577^{* * *}$} & $\log (\operatorname{sigma})$ & \multicolumn{2}{|l|}{$-2.598 * * *$} \\
\hline aic & \multicolumn{2}{|l|}{-2.237} & aic & \multicolumn{2}{|l|}{-2.265} \\
\hline bic & \multicolumn{2}{|l|}{-2.217} & bic & \multicolumn{2}{|l|}{-2.243} \\
\hline $\mathrm{N}$ & \multicolumn{2}{|l|}{3302} & $\mathrm{~N}$ & \multicolumn{2}{|l|}{3221} \\
\hline \multicolumn{3}{|c|}{$\begin{array}{l}\text { Notes: i) The regime regressors are } \alpha \text { and lagged } \\
\text { volatility, ii) Regime } 1 \text { is the high-volatility one. iii) The } \\
\text { test of "H0: } r g 1 . i d A u . B 1.0_{t}=r g 2 . i d A u . B 1.0_{t} \text { " yields } \\
\left.\chi^{2}=0.750 \text { (p.value }=0.386\right) .\end{array}$} & \multicolumn{3}{|c|}{$\begin{array}{l}\text { Notes: i) The regime regressors are } \alpha \text { and lagged } \\
\text { volatility, ii) Regime } 1 \text { is the high-volatility one. iii) The } \\
\text { test of "H0: } r g 1 . i d A u . B 1.0_{t}=r g 2 . i d A u . B 1.0_{t} \text { " yields } \\
\chi^{2}=270.37(\text { p.value }=0.000) .\end{array}$} \\
\hline
\end{tabular}


Figure 6: Auction cycle for different auctions: 5 BTP 10-year

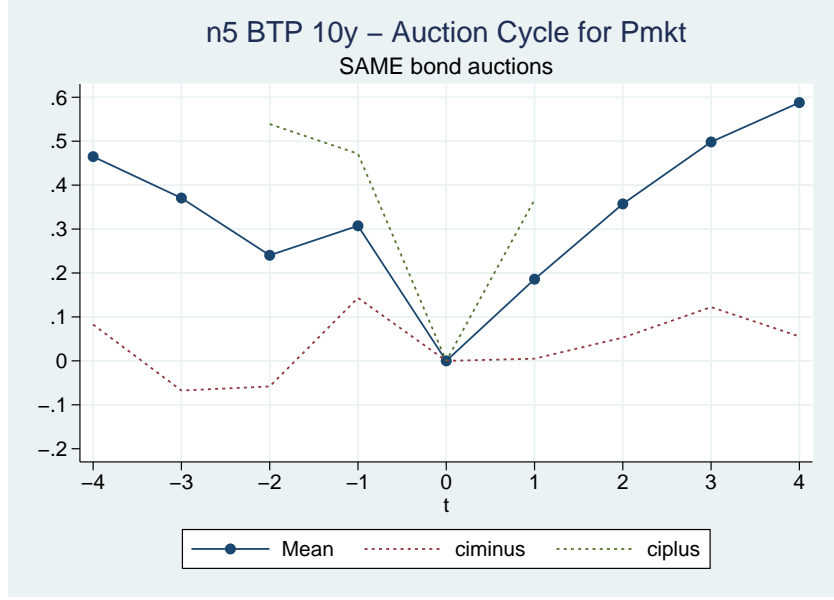

Notes: 41 auction events, values above 0.6 are not reported. n5 BTP 10y - Auction Cycle for Pmkt OTHER bonds auctions

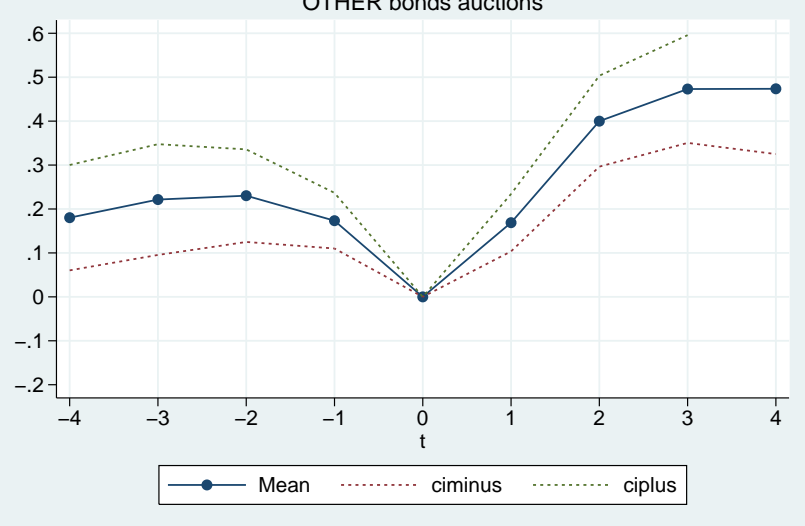

Notes: 263 auction events.

auctions at times of higher volatility, while the 5-year and 3-year BTPs do to a smaller extent. ${ }^{22}$

\subsection{A robustness check: the case of five 10-year BTPs}

This section is to consider as a robustness check of the results in section 4.1 . We use the price series of the five 10-year BTP kindly provided by MTS. The variable used here is again Dif1, but it is now constructed by using price quotes: $\operatorname{Dif} 1_{t}^{b}=P m k t_{t}-P m k t_{0}$ where $t=-4, \ldots, 4 .^{23}$ The left-side chart of Figure 6 reports the auction cycle obtained by considering the effect of bond-X auctions on the market value of bond $\mathrm{X}$ (same bond, $X=1-5,41$ cases); differently, the right-side chart is obtained by considering the effect of bond-Y auctions on the market value of bond $X$ (other bonds, $Y=1-21,263$ cases).

The typical pattern of the auction cycle emerges in both cases; of course, it is not an inverted V-shaped pattern now since we consider the price and not the yield. It is somehow surprising that the effect is comparable across the two groups of auctions: a deeper effect in case of auctions of the same bond is what we expected. This might suggest that bonds with the same maturity are highly fungible.

We also check the influence of auctions by considering the distribution of the effect across all the auctions available through the same checks discussed in section 4.1 (cycle width), the results are reported in Table 7. The values show that a decrease of Pmkt at the auction day (ckA1) is observed in the majority of the cases. This is followed by an increase (ckA2) in half of the cases when auctions of the same bond are considered, while the share is smaller in case of auctions of other bonds. The auction cycle has a 4-day width (ckB2) only

\footnotetext{
${ }^{22}$ The lack of significance of the $d A u . B 1.0_{t}$ coefficient in the High-Volatility regime for the BTP-5y and BTP-3y might reflect a truly softer effect for these two bonds, but it might also depend upon the small number of observations assigned to the high-volatility regime with respect to the low-volatility (Figure 8 and 9 in Appendix I).

${ }^{23}$ Our choice is to use directly the price values obtained by MTS and not to convert them into yields because there is no guarantee to obtain perfect comparability with the yields calculated by Banca d'Italia, and because results in terms of price are directly comparable to those in terms of yields given the fix relationship between prices and yields.
} 
Table 7: Check of the Auction cycle width

\begin{tabular}{c|c}
\hline SAME bond & OTHER bonds \\
\hline 41 auctions & 263 auctions \\
ckA1 $=27(65.8 \%) ;$ & ckA1=157 $(59.7 \%) ;$ \\
ckA2 $=21(51.0 \%)$ & ckA2=110(41.7\%); \\
ckB2 $=8(19.6 \%)$ & ckB2=49(18.7\%) \\
\hline
\end{tabular}

in a very limited number of cases. On the whole, the results in this section are consistent with the analysis in section 4.1, which therefore can be judged robust.

\subsection{Discussion of the results}

The analysis in this section shows that a positive increase of the market yield is observed at the auction day in the vast majority of the cases. However, the so-called auction cycle found by previous contributions seems more a result of aggregation than a pattern observable in a relevant number of auctions when a time span wider than the auction day is considered. This emerges both from the distribution across all the auctions available and through regression analysis based on the ARMA approach. Furthermore, auctions of new bonds (group-A auctions) have a deeper effect on the MRY of an already traded bond than further auctions of the same bond. This is likely to depend upon the specialness of such issues as discussed in section 3.

The influence of auctions on the secondary market seems to depend also on the level of volatility in the market when this is particularly high. Particularly for the CTZ, this result is comparable with Beetsma et al.'s (2014). However, Markov-switching estimations seem to suggest that this does not apply to all the GBs with the same strength: the longest and the shortest maturity bonds considered provide clearer evidence in this direction. Furthermore, the robustness analysis suggests that the market value of bonds is influenced in a similar way by auctions of their own as well as by auctions of bonds with the same formal maturity but different residual life.

\section{Auction results with respect to Market values}

The result of an auction is the price paid by the primary dealer to get the ownership of the bond. It comes natural to compare auction results with contemporaneous market quotes. Underpricing is the common finding in this kind of analyses; to wit, the auction price results lower than the reference market price chosen. Breedon and Ganley (2000) find underpricing by considering auctions of UK's GBs. ${ }^{24}$ Goldreich (2007) considers auctions of US's GBs and he finds underpricing too regardless of the auction mechanism applied. Also Lou

\footnotetext{
${ }^{24}$ By using data on auctions of UK's GBs, they show that when the reference market price is selected with caution, the size of such underpricing is much smaller.
} 
et al. (2013) study auctions of US's GBs and they report underpricing as well.

We now aim to compare auction results with contemporaneous market quotes, we are not aware of any previous result about this for Italy. Such comparison is to run and interpret with caution because of different reasons. Firstly, if the auction cycle occurred (even when limited at the auction day only), the market price would be endogenous with respect to the auction event even before the auction takes place. As a consequence, the comparison could result biased. Secondly, auctions of Italian GBs take place from 9.00 am to 11.00 am of the auction day (MEF, 2015b), the auction result is published shortly after $11.00 \mathrm{am}$, it is therefore likely to influence the secondary-market during the same day of the auction. This can trouble the comparison when daily market quotes are available instead of tick-by-tick data. Thirdly, the reference market quote to use for the comparison is to select with caution. Indeed, even though fungible, comparison with quotes of a bond different than the auctioned one might be misleading.

There is a further issue to consider when comparing Italy's auction results with contemporaneous market quotes from the Treasury perspective. As matter of fact, the official results reported are misleading for this purpose because there is an extra cost borne by the Treasury which decreases the price paid in the end by the primary dealers. Indeed, for medium/long term bonds (those considered in our analysis) primary dealers are forbidden to levy a commission on their customers for the purchasing order they execute on their behalf. A compensation for this is paid to them indirectly by the Italian Treasury. This is quantified as a fixed percentage of the face value of the bond auctioned (MEF, 2015a). As said, the amount of such compensation is not included in the price nor in the yield published as a result of the auction because these are addressed to the end investors. Then, they do not reflect exactly the return received (cost borne) by the Treasury which is lower (higher) for the amount of the compensation (MEF, 2013a). ${ }^{25}$

All this said, we proceed to the analysis which is designed to take these issues into account as explained in the next subsection. Given that we need to include the compensation paid, we need to work directly with prices: auction price net of the compensation and market price. We can therefore develop this analysis only for the five BTPs obtained from MTS (MTS provided us with the price series) and for the CTZ whose price can be retrieved directly from yields since these are zero-coupons bonds.

\footnotetext{
${ }^{25}$ Just formally, the compensation is acknowledged by the Treasury to Banca d'Italia for running the auction, but Banca d'Italia turns it to the primary dealers because they cannot levy commissions on their customers. Banca d'Italia has not to turn it to the primary dealers, but it always does it. The exact amount that will be transferred to the PDs is made known through an announcement reporting the auction details, generally 7 days before the auction. Then, the primary dealer pays $(P a u c-C)+A I$ to the Treasury, where $C$ is the compensation acknowledged and $A I$ is the accrued-interest; while the customer pays $P a u c+A I$ to the primary dealer (Banca d'Italia 2015, "Convenzione tra la Banca d'Italia gli operatori ammessi a partecipare alle operazioni di collocamento, acquisto e concambio di Titoli di Stato"). It is to say that the Italian Treasury does not use strategically such compensation: this has changed only once in the period January 2002 to December 2014 (the Treasury has decreased it from higher levels in April 2014 by saying that market conditions have changed). Differently, for short-term bonds (1-year, so-called BOT, not considered in this paper) primary dealers may apply a commission quantified by law to their customers.
} 


\section{Outline of the analysis}

Our purpose is to compare the auction price, net of the compensation paid to the primary dealers, with a reference market price (clean price). The compensation-adjusted Auction Price (Pauc*) is simply calculated as the difference between the official auction price $($ Pauc) and the right amount of compensation granted $(C)$ : Pauc* $=$ Pauc $-C{ }^{26}$

As for the reference market price, any comparison should regard the market price that would be in case of no-auction. It goes without saying that the issue is to quantify such would-be-price. Among others, Breedon and Ganley (2000) compare the two prices directly after some adjustments, Goldreich (2007) uses the quote in the when-issued market, Lou et al. (2013) use the average of the MRY at different dates around the auction. We apply the same procedure as in Lou et al. (2013) for the construction of the reference market price, we therefore consider circles around the auction day. The first reference price $\left(P m k t_{0}^{*}\right)$ coincides with the market price $P m k t_{t}$ at the auction day $(t=0)$, the second $\left(P m k t_{ \pm 1}^{*}\right)$ is obtained as the average of $P m k t_{t=-1}$ and $P m k t_{t=+1}$, the third $\left(P m k t_{ \pm 2}^{*}\right)$ is obtained as the average of $P m k t_{t=-2}$ and $P m k t_{t=+2}$, so on and so forth up to $P m k t_{ \pm 4}^{*}$; we recall that Pmkt is the intra-day average value (clean price).

Eventually, the comparison is based on the Dif 2 variable defined as Dif $2_{t}=P a u c_{0}^{*}-P m k t_{t}^{*}$ for $t=$ $0, \pm 1, \pm 2, \pm 3, \pm 4$. In order not to consider marginal observations, values of $D$ if $2_{t}<0.01$ are set equal to zero (alias, differences below $1 €$ cent). As said, the analysis is only for the five 10-year BTPs obtained from MTS and for the CTZ because for these we have, or could retrieve from yields, the series of the market price on which to construct $P m k t_{t}^{*}{ }^{27}$

A distinguishing figure of the previous works cited (Breedon and Ganley, 2000; Goldreich, 2007; Lou et al., 2013 ) is that those consider mainly the average of the differences across all the auctions in the sample, but not the distribution of such differences. Differently, we will consider both, but we give more emphasis to the distribution. In addition, we ensure a perfect matching between the auctioned bond and the bond whose

\footnotetext{
${ }^{26}$ The amount of the compensation granted to the primary dealers is defined with respect to the maturity of the bond, its values are in Table 15 in Appendix I. As said, it changed only once in the period January 2002 - December 2014. However, since the 30th December 2009, the compensation granted has been linked to the residual life of the bond at the auction date. Then, for this sub-period, if the residual life of the 10-year BTP auctioned is below 7.5 years, the compensation of the 5-year BTP is granted to the primary dealers which bought it at the auction. Moreover, BTPs with a 7-year maturity have been also issued since January 2014. Then, for the period January-December 2014: if the residual life of the 10-year BTP auctioned is below 6 year, the compensation of the 5-year BTP is granted; if its residual life is between 6 and 8.5 years, the one of the 7-year BTP is granted; if it is more than 8.5 years, the compensation of the 10 -year BTP is granted. A residual life much shorter than the formal maturity of the bond is the case for group-B.2 auctions.

${ }^{27}$ Theoretically, we could have converted $P a u c^{*}$ into yields, and compare it with the yield series used in section 4 or, alternatively, retrieve prices from those yield series and compare them with Pauc*. The problem is that for the BTPs we miss the information on the accrued interest and the algorithm used by Banca d'Italia to solve the formula in Appendix Ila. Differently, a CTZ does not pay any coupon and the formula in Appendix Ila has a closed form solution. We need the highest degree of accuracy possible for the comparison since we deal with very small numbers. We therefore preferred to be on the safe side and do it only for the five 10-year BTPs whose market price series we obtained directly from MTS and for the CTZ whose market price series can be retrieved safely from the yield series published by Banca d'Italia.
} 
Table 8: n5 10-year BTP: Dif $2_{t}$

\begin{tabular}{|c|c|c|c|c|c|c|}
\hline \multicolumn{5}{|c|}{ Panel A } & \multicolumn{2}{|c|}{ Panel B } \\
\hline \multicolumn{5}{|c|}{ group-B.1 auctions } & \multirow[b]{2}{*}{ correl. } & \multirow[b]{2}{*}{ Dif $2_{0}$} \\
\hline $\mathbf{t}+/-$ & $\mathrm{N}==$ & Mvalue & $\operatorname{dif} 2>0$ & $\operatorname{dif} 2=0$ & & \\
\hline 0 & 28 & -0.021 & 16 & 5 & $\mathrm{BCr}$ & $0.382 *$ \\
\hline 1 & 28 & -0.215 & 12 & 1 & $\mathrm{iA}$ & 0.075 \\
\hline 2 & 28 & -0.312 & 15 & 0 & mry & -0.280 \\
\hline 3 & 28 & -0.404 & 17 & 0 & V.mry & -0.301 \\
\hline 4 & 28 & -0.472 & 19 & 0 & & \\
\hline
\end{tabular}

Notes: "BCr" is the bid/cover ratio, "iA" is the amount sold, "mry" is the

market yield, "V.mry" is the 5-day standard deviation of the mry, * stands

for significance at $5 \%$ of the estimated coefficient.

secondary-market quote is taken as reference.

\section{The five 10-year BTPs}

The five BTPs used are those described in section 3 and already used in section 4.3. We match the auction results of these bonds $\left(\mathrm{Pauc}^{*}\right)$ with the reference market price of the same bonds $\left(P m k t^{*}\right)$. On the whole, there are 41 auctions available for these five bonds: 5 are group-A auctions, 28 group-B.1, and 8 are group-B.2. We consider group-B.1 auctions, alias, those auctions of the five BTPs when these are the on-the-run bond. Statistics for Dif $2_{t}$ are in Table 8-Panel A.

At the auction day $\left(\right.$ Dif $\left.2_{0}\right)$, the auction price results higher than the market price $57.1 \%(16 / 28)$ of the times and they are equal to each other $17.8 \%(5 / 28)$. Given the values in Table 2 about the auction cycle width for the 10-year BTP, the 1-day circle $\left(\right.$ Dif $\left.2_{1}\right)$ is the most relevant to consider among the four defined. As for this, the auction price results higher than the market price $44.4 \%(12 / 28)$ of the cases. Wider circles show an increasing number of positive Dif 2 values.

By focusing on the auction day only, the left-side chart in Figure 10 (Appendix I) plots the Dif $2_{0}$ values. The negative mean value of Dif $2_{0}$ in Table 8 depends upon the large values of the few negative observations with respect to the more numerous positive which are smaller. We check also whether the bid-to-cover ratio (i), the amount offered (ii), the volatility (iii), and the level of the MRY at the auction day (iv) are significantly correlated with $\operatorname{Dif} 2_{0}$ (Table 8-Panel B). Only the bid-to-cover ratio emerges as statistically significant, but the number of observations is limited and this might have deflated the significance of the other variables. 
Table 9: CTZ: Dif $2_{t}$

\begin{tabular}{|c|c|c|c|c|c|c|}
\hline \multicolumn{5}{|c|}{ Panel A } & \multicolumn{2}{|c|}{ Panel B } \\
\hline \multicolumn{5}{|c|}{ group-B.1 auctions } & \multirow[b]{2}{*}{ correl. } & \multirow[b]{2}{*}{ Dif $2_{0}$} \\
\hline $\mathbf{t}+/-$ & $\mathbf{N}==$ & Mvalue & $\operatorname{dif} 2>0$ & $\operatorname{dif} 2=0$ & & \\
\hline 0 & 44 & 0.034 & 36 & 4 & $\mathrm{BCr}$ & $0.444^{*}$ \\
\hline 1 & 44 & -0.019 & 21 & 4 & iA & $-0.022^{*}$ \\
\hline 2 & 43 & -0.047 & 24 & 0 & mry & -0.033 \\
\hline 3 & 43 & -0.092 & 19 & 3 & V.mry & $-0.466^{*}$ \\
\hline 4 & 43 & -0.150 & 16 & 2 & & \\
\hline
\end{tabular}

Notes: "BCr" is the bid/cover ratio, "iA" is the amount sold, "mry" is the

market yield, "V.mry" is the 5-day standard deviation of the mry, * stands

for significance at $5 \%$ of the estimated coefficient.

\section{The CTZs}

The CTZs are zero-coupon bonds, prices can therefore be retrieved directly from yields once the maturity date of the underlying CTZ is known (formula in Appendix Ila). Then, we could use the MRY series of the CTZ (studied in section 4) to develop an analysis of Pauc* vs Pmkt*. However, the analysis is for the sub-period March 2010 to December 2014 only, because we know exactly the ISIN of the benchmark bond under the market-yield series just for this sub-period. ${ }^{28}$ The analysis comprises only group-B.1 auctions because Pauc* and $\mathrm{Pmkt}^{*}$ are those of the same bond only for these. The number of matches available is 44 , statistics for Dif $2_{t}$ are in Table 9-Panel A.

Dif $2_{0}$ shows that in almost all cases Pauc* is higher than Pmkt* at the auction day $\left(\right.$ Dif $\left.2_{0}>0\right)$. Given the values in Table 2 for the CTZ, even the 1-day circle is not much relevant for the CTZ because an auction cycle over two days is just for $36.6 \%$ of the observations. In any case, Dif $2_{1}$ shows that the share of positive observations is as much as of the negative ones.

Focusing on the auction day only, the right-side graph in Figure 10 (Appendix I) plots the Dif $2_{0}$ values; the values available are more equally spread along the period considered in this case. After recalling that the turmoil in Italy's GBs market spreads roughly over the July 2011 to January 2013 period (Cafiso, 2014), interestingly the graph shows that the few negative values observed are all concentrated in this period. The correlation of Dif $2_{0}$ with the bid-to-cover ratio (i), the amount offered (ii), the volatility (iii) and the level of the MRY (iv) are in Table 9-Panel B. The correlation with the bid-to-cover ratio is positive and statistically significant (as for the BTPs previously discussed), the one with volatility is negative and statistically significant (it was negative as well, but not significant for the BTPs).

Finally, we have a look at group-A auctions as well for the CTZ since 13 observations are available. As

\footnotetext{
${ }^{28}$ Banca d'Italia provided us with this information only for this sub-period, this allowed us to know the maturity date of the underlying bond necessary to retrieve prices from yields.
} 
for these, the reference market price $\left(P m k t^{*}\right)$ is the one of the on-the-run bond which will be replaced by the auctioned bond a couple of days after the auction. Then, we are comparing prices of different bonds in this case. We just consider Dif $2_{0}$ because symmetric circles around the auction cannot be constructed. ${ }^{29}$ Such few observations suggest a very different picture for group-A auctions with respect to the group-B1 previously discussed. Indeed, Dif $2_{0}$ is always negative for group-A auctions, meaning Pauc $<$ Pmkt, with an average value of -1.11 . Different results for group-A auctions are in line with the output of the ARMA estimations in Table 4.

\section{Discussion of the results}

Differently from what found by previous works which consider other countries than Italy, the analysis in this section does not suggest underpricing of Italy's GBs at auctions, neither with respect to the auction day nor to the days around the auction. Even though the sample is limited, this emerges from very different bonds: coupon and zero-coupon bonds, long and medium maturity bonds (CTZ and BTP). This finding is achieved through the comparison of the auction result of a bond with the contemporaneous market quote of the same bond auctioned (group-B.1 auctions). In this regard, we believe that the accuracy of the comparison done is the highest possible.

Differently from group-B.1, group-A auctions of the CTZ signal underpricing (Pauc $<$ Pmkt) when compared to the on-the-run bond which they are going to replace. Admittedly, this emerges from a very small sample. The robustness of this result should therefore be checked further, but there is no reason to suspect that the small sample used has conditioned somehow this result.

The bid-to-cover ratio is moderately correlated (positively) with the difference observed at the auction day (both for the BTPs and the CTZ). Given that the vast majority of the differences is positive (Pauc $>$ Pmkt) at the auction day, this lets us to suppose that the higher the demand with respect to the supply of bond, the higher the positive difference between the auction price and the market price might be. To wit, the Treasury gets a relatively higher price when demand is high as one would expect. Differently, based on the negative correlation with volatility, although statistically significant only for the CTZ, when higher levels of volatility are observed, the Treasury might get a price relatively closer to the market one.

\footnotetext{
${ }^{29}$ The benchmark is going to be the auctioned bond after the auction, while it is the previous on-the-run up to the auction day (included).
} 


\section{Conclusions}

The object of this paper has been the relationship between Treasury auctions and contemporaneous market quotes. We have preferred to talk of the relationship between the two, and not of the effect of auctions on the secondary market, because even though auctions are exogenous events, their result is not with respect to the secondary market evolution. Indeed, as explained in the paper, both the primary and the secondary market list among their main players the same financial institutions which are likely to base and modify their bids for contemporaneous quotes in the secondary market. This consideration must be kept in mind when reading the results of our analysis as well as those of works which have a similar object.

On the whole, our analysis provides results which question some of those found in previous contributions. As for the so-called auction cycle, data on Italy shows it too, but our analysis demonstrates that it is more a result of aggregation across auctions than a widespread pattern. Unfortunately, there are no checks similar to ours for other countries, then we do not know whether this would be the case for them as well. Differently, a yield increase just at the auction day is often observed as in previous contributions. Based on some bonds, the amount of such increase seems to depend upon the market volatility at the time of auctions. Beetsma et al. (2014) justify this through their explanation of the auction cycle based on limited risk-bearing capacity of the primary dealers. However, as said in section 2, this is a hypothesis difficult to test. As matter of fact, higher volatility, by reflecting higher risk, is likely to change practices both for the primary dealers and the Treasury as well (Albertazzi et al., 2014). Indeed, our data show that also the Italian Treasury partly changed its issuing policy during the turmoil periods covered by our analysis. With regard to the 10 -year benchmark bond, it issued many times off-the-run bonds in such periods, a practice which it does not follow in normal times.

In contrast to previous contributions which provide results for countries other than Italy, underpricing does not emerge from Italian auctions. Admittedly, this finding is obtained from a sample with a limited number of auctions, but there is no reason to suppose that the sample has driven the result since it comprises auctions of different bonds, with very different maturities, along a reasonably long period. To our knowledge, there is no other work which systematically compares the result of Treasury auctions with contemporaneous market quotes for Italy. This may also depend upon the difficulties which the compensation paid by the Treasury to the primary dealers poses; we corrected for it in our analysis. As for the amount of the difference between the auction result and contemporaneous market quotes, this seems moderately correlated with the bid-to-cover ratio and with volatility in a sensible way. 


\section{References}

AFME (2014), European Primary Dealers Handbook, Association for Financial Markets in Europe, Brussels \& London. 1, 2, 3

Albertazzi, U., Ropele, T., Sene, G. and Signoretti, F. M. (2014), 'The impact of the sovereign debt crisis on the activity of italian banks.', Journal of Banking and Finance 46, 387 - 402. 25

Andritzky, J. (2012), Government Bonds and Their Investors: What Are the Facts and Do They Matter?, Working Paper WP/12/158, International Monetary Fund. 1

Banca d'Italia (2014), Supplementi al Bollettino Statistico - No. 67, indicatori monetari e finanziari edn, Banca d'Italia, Roma. 6

Beetsma, R., Giuliodori, M., de Jong, F. and Widijanto, D. (2014), 'Price Effects of Sovereign Debt Auctions in the Euro-zone: The Role of the Crisis', Journal of Financial Intermediation. Available online 4 December 2014. $3,4,5,9,10,11,12,14,25$

Beltran, D., Kretchmer, M., Marquez, J. and Thomas, C. (2013), 'Foreign holdings of US Treasuries and US Treasury yields', Journal of International Money and Finance 32, 1120-1143. 1

Breedon, F. and Ganley, J. (2000), 'Bidding and Information: Evidence from Gilt-edged Auctions', The Economic Journal 110(466), 963-984. 19, 21

Cafiso, G. (2014), Debt Sustainability in the case of External Debt. An analysis based on Italy's Treasury auctions, Working Paper 5021, CESifo. 1, 5, 23

Dottori, D. and Manna, M. (2015), Strategy and tactics in public debt management, Working Papers 1005, Banca d'Italia, Rome. 9

Enders, W. (2009), Applied econometric time series, 3rd edn, John Wiley \& Sons. 12

Filardo, A. J. (1994), 'Business-cycle phases and their transitional dynamics', Journal of Business \& Economic Statistics 12(3), 299-308. 16

Fleming, M. J. and Rosenberg, J. V. (2007), How do Treasury dealers manage their positions?, Federal Reserve Bank of New York Staff Reports 299. 4, 9

Frühwirth-Schnatter, S. (2006), Finite mixture and Markov switching models: Modeling and applications to random processes, Springer Science \& Business Media. 16

Goldreich, D. (2007), 'Underpricing in Discriminatory and Uniform-Price Treasury Auctions', The Journal of Financial and Quantitative Analysis 42, 443-466. 1, 3, 5, 19, 21

Gros, D. (2013), 'Banking Union with a Sovereign Virus.', Intereconomics 48(2), 93-97. 6 Hamilton, J. D. (2008), 'Regime-switching models', The new palgrave dictionary of economics 2. 16 
Jagannathan, R., Jirnyi, A. and Sherman, A. G. (2014), 'Share auctions of initial public offerings: Global evidence', Journal of Financial Intermediation (0), -. 5

Keane, F. (1996), Repo rate patterns for new Treasury notes, Current Issues in Economics and Finance 10, Federal Reserve Bank of New York. 7

Keloharju, M., Nyborg, K. G. and Rydqvist, K. (2005), 'Strategic Behavior and Underpricing in Uniform Price Auctions: Evidence from Finnish Treasury Auctions', The Journal of Finance 60(4), 1865-1902. 5

Kremer, I. and Nyborg, K. G. (2004), 'Underpricing and Market Power in Uniform Price Auctions', Review of Financial Studies 17(3), 849-877. 5

Krishnamurthy, A. and Vissing-Jorgensen, A. (2012), 'The aggregate demand for Treasury debt', Journal of Political Economy 120(2), 233-267. 4, 7

Lou, D., Yan, H. and Zhang, J. (2013), 'Anticipated and repeated shocks in liquid markets', The Review of Financial Studies 26(8), 1891-1912. 1, 3, 4, 5, 9, 10, 11, 19, 21

Massa, M. and Simonov, A. (2003), 'Reputation and interdealer trading: A microstructure analysis of the treasury bond market', Journal of Financial Markets 6(2), 99-141. 3

MEF (2011), Selezione e Valutazione degli Specialisti in titoli di Stato, number 993039, Ministero dell'Economia e delle Finanze. November. 3

MEF (2013a), Decreto per le aste dei Titoli di Stato - 5 Giugno 2013, Ministero dell'Economia e delle Finanze, Roma. 20

MEF (2013b), Elenco degli Specialisti in Titoli di Stato, Ministero dell'Economia e delle Finanze, Roma. 3 MEF (2015a), Decreto per la trasparenza nel collocamento dei Titoli di Stato - 15 gennaio 2015, Ministero dell'Economia e delle Finanze, Roma. 20

MEF (2015b), Modalità di svolgimento delle aste, Ministero dell'Economia e delle Finanze, Roma. 20

Merler, S. and Pisani-Ferry, J. (2012), Who's afraid of sovereign bonds?, Bruegel Policy Contribution 2012/02, Bruegel. 6

Missale, A., Giavazzi, F. and Benigno, P. (2002), 'How is the Debt Managed? Learning from Fiscal Stabilizations', Scandinavian Journal of Economics 104(3), 443-469. 2

Rogers, J. H., Scotti, C. and Wright, J. H. (2014), 'Evaluating asset-market effects of unconventional monetary policy: a multi-country review', Economic Policy 29(80), 749-799. 2

Sundaresan, S. (1994), 'An empirical analysis of US Treasury auctions: Implications for auction and term structure theories', The Journal of Fixed Income 4(2), 35-50. 7

Szczerbowicz, U. (2012), The ECB unconventional monetary policies: have they lowered market borrowing costs for banks and governments?, Working Paper 2012-36, CEPII, Paris. 4 
Thaler, R. H. (1988), 'Anomalies: The winner's curse', The Journal of Economic Perspectives 2(1), 191-202. 5

Wolswijk, G. and De Haan, J. (2005), Government debt management in the euro area: recent theoretical developments and changes in practices, Occasional Paper Series 25, ECB. 1 


\section{Appendix I. Tables and figures}

Table 10: abs $(\triangle M R Y)$ summary statistics

\begin{tabular}{l|l|l|l|l}
\hline & absdiff_btp10y & absdiff_btp5y & absdiff_btp3y & absdiff_ctz \\
\hline obs & 3307 & 3307 & 3307 & 3242 \\
mean & 0.039 & 0.047 & 0.048 & 0.047 \\
sd & 0.047 & 0.061 & 0.073 & 0.074 \\
$\min$ & 0.000 & 0.000 & 0.000 & 0.000 \\
$\max$ & 0.824 & 0.964 & 1.112 & 1.083 \\
p25 & 0.012 & 0.014 & 0.013 & 0.012 \\
p50 & 0.027 & 0.031 & 0.030 & 0.027 \\
p75 & 0.048 & 0.057 & 0.055 & 0.053 \\
\hline
\end{tabular}

Table 11: BTP 10y - Auction Cycle values by Volatility level (Dif $\left.1_{t}\right)$

\begin{tabular}{l|ll|ll|ll|ll|ll} 
btp10y & ALL & & $75 p c$ & & $50 p c$ & & $25 p c$ & & $1 p c$ & \\
\hline idauc4 & mean & sd & mean & sd & mean & sd & mean & sd & mean & sd \\
\hline-4 & -0.039 & 0.119 & -0.125 & 0.183 & -0.004 & 0.085 & -0.015 & 0.048 & -0.012 & 0.050 \\
-3 & -0.030 & 0.111 & -0.087 & 0.189 & -0.011 & 0.075 & -0.013 & 0.046 & -0.009 & 0.030 \\
-2 & -0.026 & 0.081 & -0.071 & 0.130 & -0.009 & 0.062 & -0.011 & 0.035 & -0.013 & 0.031 \\
-1 & -0.022 & 0.059 & -0.046 & 0.101 & -0.022 & 0.037 & -0.009 & 0.032 & -0.007 & 0.018 \\
0 & 0.000 & 0.000 & 0.000 & 0.000 & 0.000 & 0.000 & 0.000 & 0.000 & 0.000 & 0.000 \\
1 & -0.022 & 0.064 & -0.030 & 0.093 & -0.013 & 0.052 & -0.038 & 0.065 & -0.012 & 0.033 \\
2 & -0.048 & 0.100 & -0.094 & 0.138 & -0.031 & 0.087 & -0.058 & 0.081 & -0.008 & 0.058 \\
3 & -0.057 & 0.131 & -0.127 & 0.202 & -0.031 & 0.092 & -0.060 & 0.090 & -0.011 & 0.072 \\
4 & -0.053 & 0.162 & -0.119 & 0.258 & -0.025 & 0.123 & -0.062 & 0.107 & -0.011 & 0.076 \\
\hline Total & -0.033 & 0.103 & -0.077 & 0.163 & -0.016 & 0.076 & -0.030 & 0.067 & -0.009 & 0.047 \\
sum & -0.297 & & -0.698 & & -0.147 & & -0.266 & & -0.083 & \\
sumABS & 0.297 & & 0.698 & & 0.147 & & 0.266 & & 0.083 & \\
N & 126 & & 32 & & 40 & & 27 & & 27 &
\end{tabular}

Table 12: BTP 5y - Auction Cycle values by Volatility level $\left(\right.$ Dif $\left.1_{t}\right)$

\begin{tabular}{|c|c|c|c|c|c|c|c|c|c|c|}
\hline btp5y & ALL & & $75 p c$ & & $50 \mathrm{pc}$ & & $25 p c$ & & $1 \mathrm{pc}$ & \\
\hline idauc4 & mean & sd & mean & sd & mean & sd & mean & sd & mean & sd \\
\hline-4 & -0.017 & 0.179 & -0.060 & 0.315 & -0.009 & 0.123 & -0.025 & 0.097 & 0.020 & 0.125 \\
\hline-3 & -0.006 & 0.166 & 0.005 & 0.345 & 0.001 & 0.076 & -0.020 & 0.051 & -0.007 & 0.033 \\
\hline-2 & -0.006 & 0.131 & 0.003 & 0.266 & -0.002 & 0.078 & -0.016 & 0.041 & -0.008 & 0.023 \\
\hline-1 & -0.010 & 0.065 & -0.008 & 0.118 & -0.020 & 0.055 & -0.011 & 0.038 & -0.002 & 0.022 \\
\hline 0 & 0.000 & 0.000 & 0.000 & 0.000 & 0.000 & 0.000 & 0.000 & 0.000 & 0.000 & 0.000 \\
\hline 1 & -0.016 & 0.101 & -0.024 & 0.193 & -0.012 & 0.054 & -0.011 & 0.049 & -0.017 & 0.055 \\
\hline 2 & -0.043 & 0.147 & -0.110 & 0.262 & -0.018 & 0.118 & -0.026 & 0.060 & -0.026 & 0.073 \\
\hline 3 & -0.056 & 0.169 & -0.133 & 0.308 & -0.042 & 0.121 & -0.028 & 0.071 & -0.033 & 0.085 \\
\hline 4 & -0.061 & 0.176 & -0.145 & 0.306 & -0.053 & 0.136 & -0.020 & 0.088 & -0.040 & 0.097 \\
\hline Total & -0.024 & 0.139 & -0.053 & 0.259 & -0.017 & 0.094 & -0.017 & 0.061 & -0.012 & 0.070 \\
\hline sum & -0.214 & & -0.473 & & -0.154 & & -0.156 & & -0.112 & \\
\hline sum $A B S$ & 0.214 & & 0.488 & & 0.156 & & 0.156 & & 0.152 & \\
\hline & 109 & & 24 & & 25 & & 30 & & 30 & \\
\hline
\end{tabular}


Table 13: BTP 3y - Auction Cycle values by Volatility level $\left(\right.$ Dif $\left.1_{t}\right)$

\begin{tabular}{l|ll|ll|lll|ll|ll}
\multicolumn{1}{l}{ btp3y } & \multicolumn{1}{l}{ ALL } & \multicolumn{1}{c}{$\mathbf{7 5 p c}$} & \multicolumn{2}{c}{$\mathbf{5 0 p c}$} & \multicolumn{2}{c}{$\mathbf{2 5 p c}$} & \multicolumn{3}{c}{ 1pc } \\
\hline idauc4 & mean & sd & mean & sd & mean & sd & mean & sd & mean & sd \\
\hline-4 & -0.041 & 0.167 & -0.131 & 0.302 & -0.008 & 0.099 & -0.022 & 0.068 & -0.006 & 0.045 \\
-3 & -0.028 & 0.145 & -0.086 & 0.273 & -0.004 & 0.087 & -0.011 & 0.045 & -0.014 & 0.027 \\
-2 & -0.020 & 0.117 & -0.045 & 0.221 & -0.002 & 0.072 & -0.016 & 0.053 & -0.016 & 0.021 \\
-1 & -0.017 & 0.066 & -0.040 & 0.115 & -0.005 & 0.050 & -0.012 & 0.038 & -0.013 & 0.019 \\
0 & 0.000 & 0.000 & 0.000 & 0.000 & 0.000 & 0.000 & 0.000 & 0.000 & 0.000 & 0.000 \\
1 & -0.009 & 0.083 & -0.018 & 0.123 & 0.001 & 0.052 & -0.013 & 0.098 & -0.006 & 0.026 \\
2 & -0.019 & 0.109 & -0.047 & 0.110 & 0.006 & 0.087 & -0.020 & 0.154 & -0.014 & 0.055 \\
3 & -0.028 & 0.120 & -0.073 & 0.148 & 0.000 & 0.091 & -0.024 & 0.142 & -0.017 & 0.072 \\
4 & -0.039 & 0.151 & -0.096 & 0.182 & -0.007 & 0.152 & -0.033 & 0.162 & -0.022 & 0.076 \\
\hline Total & -0.022 & 0.117 & -0.059 & 0.187 & -0.002 & 0.085 & -0.017 & 0.100 & -0.012 & 0.045 \\
sum & -0.200 & & -0.535 & & -0.019 & & -0.150 & & -0.108 &
\end{tabular}

Table 14: CTZ - Auction Cycle values by Volatility level $\left(\right.$ Dif $\left.1_{t}\right)$

\begin{tabular}{|c|c|c|c|c|c|c|c|c|c|c|}
\hline ctz & ALL & & $75 p c$ & & $50 \mathrm{pc}$ & & $25 p c$ & & $1 \mathrm{pc}$ & \\
\hline idauc4 & mean & sd & mean & sd & mean & sd & mean & sd & mean & sd \\
\hline-4 & -0.056 & 0.180 & -0.183 & 0.301 & -0.014 & 0.095 & -0.021 & 0.091 & -0.005 & 0.037 \\
\hline-3 & -0.046 & 0.157 & -0.167 & 0.261 & 0.002 & 0.084 & -0.013 & 0.066 & -0.004 & 0.021 \\
\hline-2 & -0.032 & 0.121 & -0.111 & 0.209 & -0.002 & 0.066 & -0.011 & 0.049 & -0.001 & 0.023 \\
\hline-1 & -0.016 & 0.078 & -0.058 & 0.139 & 0.004 & 0.039 & -0.005 & 0.033 & -0.005 & 0.020 \\
\hline 0 & 0.000 & 0.000 & 0.000 & 0.000 & 0.000 & 0.000 & 0.000 & 0.000 & 0.000 & 0.000 \\
\hline 1 & -0.012 & 0.095 & -0.036 & 0.150 & 0.001 & 0.106 & -0.012 & 0.042 & 0.001 & 0.038 \\
\hline 2 & -0.011 & 0.125 & -0.054 & 0.200 & 0.014 & 0.127 & -0.011 & 0.060 & 0.008 & 0.048 \\
\hline 3 & -0.021 & 0.162 & -0.079 & 0.257 & 0.013 & 0.170 & -0.024 & 0.071 & 0.006 & 0.062 \\
\hline 4 & -0.042 & 0.206 & -0.145 & 0.302 & -0.010 & 0.240 & -0.028 & 0.073 & 0.012 & 0.092 \\
\hline Total & -0.026 & 0.138 & -0.093 & 0.226 & 0.001 & 0.121 & -0.014 & 0.059 & 0.001 & 0.045 \\
\hline sum & -0.237 & & -0.834 & & 0.007 & & -0.124 & & 0.013 & \\
\hline sum $A B S$ & 0.237 & & 0.834 & & 0.060 & & 0.124 & & 0.042 & \\
\hline $\mathrm{N}$ & 126 & & 32 & & 29 & & 32 & & 33 & \\
\hline
\end{tabular}

Figure 7: Auction cycle, group-B2 auctions.

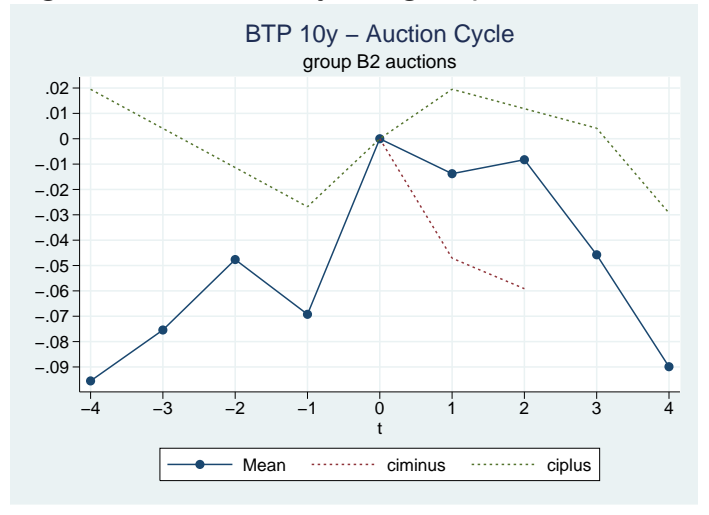

Notes: i) Based on 18 auction days, in 10 of these we observe 2 group-B2 auctions. ii) Confidence intervals below -0.09 are not reported. 
Figure 8: Smoothed Regime Probabilities

BTP 10-year

Smoothed Regime Probabilities

$\mathrm{P}(\mathrm{S}(\mathrm{t})=1)$

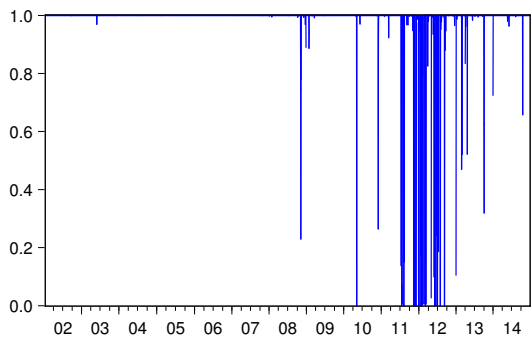

$P(S(t)=2)$

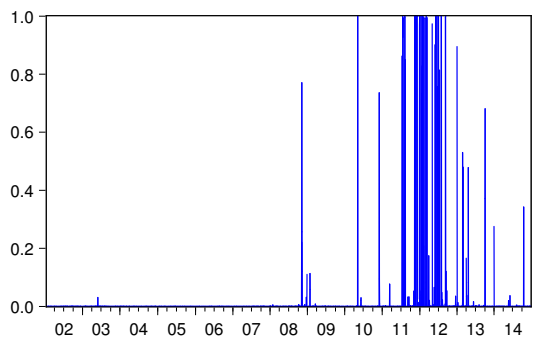

BTP 5-year

Smoothed Regime Probabilities

$P(S(t)=1)$

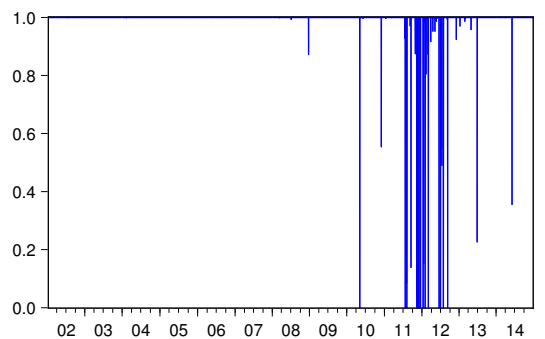

$\mathrm{P}(\mathrm{S}(\mathrm{t})=2)$

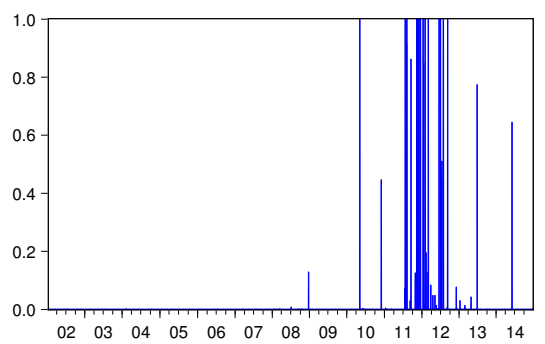

Figure 9: Smoothed Regime Probabilities

BTP 3-year

Smoothed Regime Probabilities

$P(S(t)=1)$

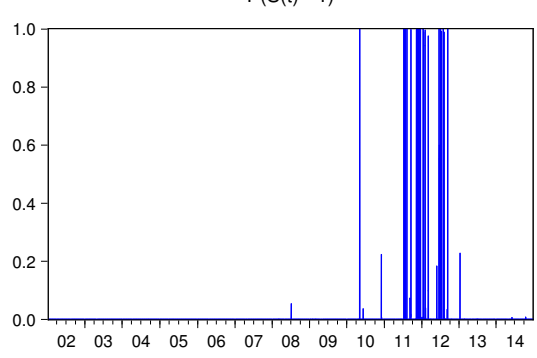

$\mathrm{P}(\mathrm{S}(\mathrm{t})=2)$

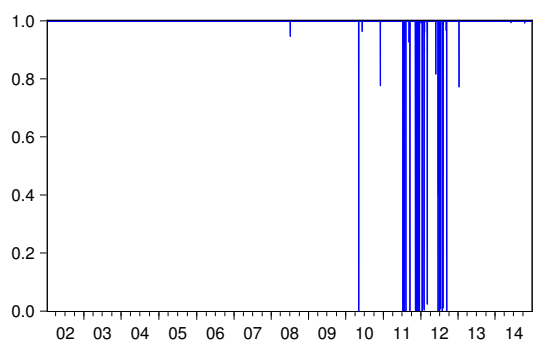

CTZ

Smoothed Regime Probabilities

$P(S(t)=1)$

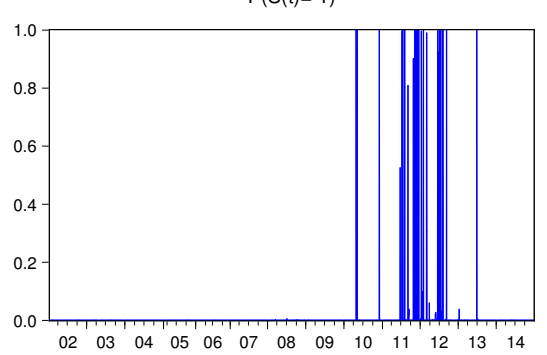

$P(S(t)=2)$

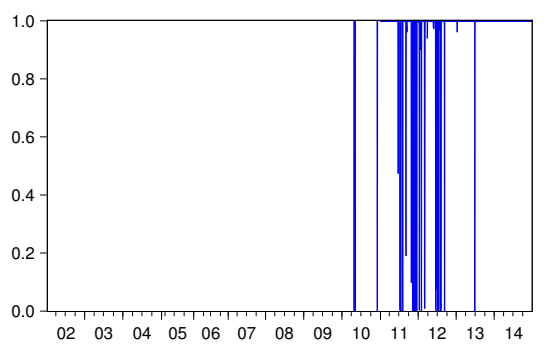


Table 15: Compensation to Primary Dealers

$\begin{array}{llllll} & \text { BTP-10y } & \text { BTP-7y } & \text { BTP-5y } & \text { BTP-3y } & \text { CTZ } \\ \text { from April 11th, 2014 } & 0.35 & 0.3 & 0.25 & 0.15 & 0.15 \\ \text { since 2002 up to April 10th, 2014 } & 0.4 & 0.35 & 0.3 & 0.2 & 0.2\end{array}$

Figure 10: Dif $2_{0}$

n5 10-year BTP

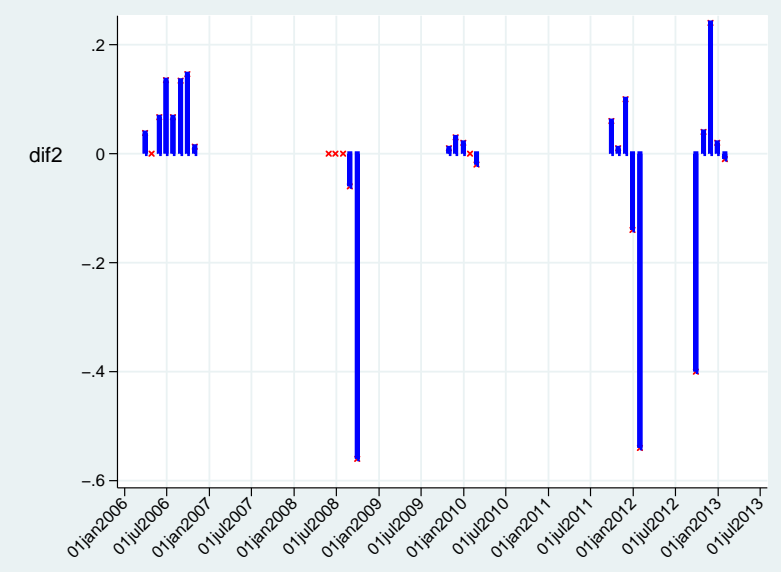

28 obs: 16 obs $>0,5$ obs $=0,7$ obs $<0$
CTZ

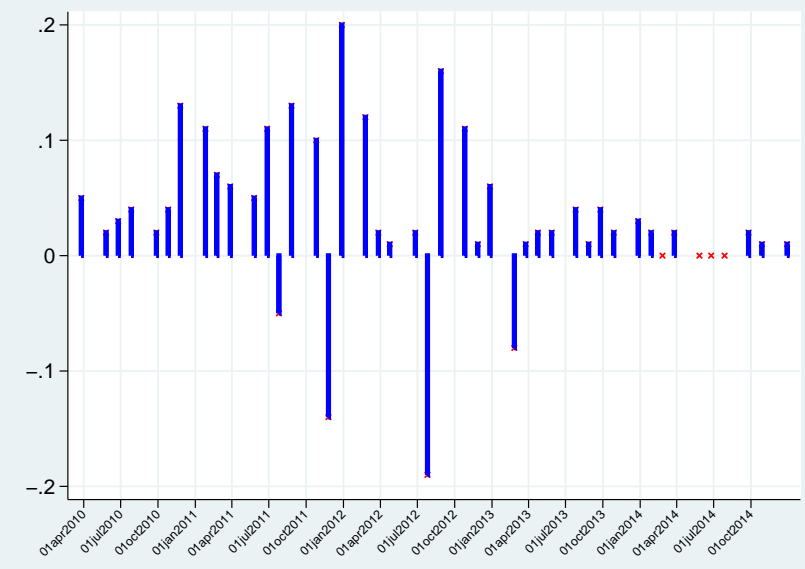

44 obs: 36 obs $>0,4$ obs $=0,4$ obs $<0$.

\section{Appendix II}

Available on-line at: https://sites.google.com/site/giancafiso/research-works/on-line-appendices (link)

\section{A) Redemption Yield Formula}

This is a simplified translation from Italian of a document made available by Banca d'Italia (2014).

\section{B) Auction-by-auction cycle graphs}

